\title{
Epigenetic interaction of microbes with their mammalian hosts
}

\author{
Ramisetti Rajeev $^{1,2, \dagger}$, Ambey Prasad Dwivedi ${ }^{1,2, \dagger}$, Anunay Sinha ${ }^{1,3, \dagger}$, \\ Viplove Agarwaal ${ }^{l, \dagger}$, Rachana Roshan Dev ${ }^{1, \dagger}$, Anjana Kar ${ }^{1, \dagger}$ and \\ SANJEEV KHOSLA ${ }^{1,4 *}$ \\ ${ }^{1}$ Centre for DNA Fingerprinting and Diagnostics (CDFD), Hyderabad, India \\ ${ }^{2}$ Graduate Studies, Manipal Academy of Higher Education (MAHE), Manipal, India \\ ${ }^{3}$ Graduate Studies, Regional Centre for Biotechnology (RCB), Faridabad, India \\ ${ }^{4}$ Institute of Microbial Technology (IMTech), Chandigarh, India \\ *Corresponding author (Email,sanjuk@imtech.res.in)
}

${ }^{\dagger}$ Ramisetti Rajeev, Ambey Prasad Dwivedi, Anunay Sinha, Viplove Agarwaal, Rachana Roshan Dev and Anjana Kar have equal contributed to this work.

MS received 26 April 2021; accepted 20 September 2021

\begin{abstract}
The interaction of microbiota with its host has the ability to alter the cellular functions of both, through several mechanisms. Recent work, from many laboratories including our own, has shown that epigenetic mechanisms play an important role in the alteration of these cellular functions. Epigenetics broadly refers to change in the phenotype without a corresponding change in the DNA sequence. This change is usually brought by epigenetic modifications of the DNA itself, the histone proteins associated with the DNA in the chromatin, non-coding RNA or the modifications of the transcribed RNA. These modifications, also known as epigenetic code, do not change the DNA sequence but alter the expression level of specific genes. Microorganisms seem to have learned how to modify the host epigenetic code and modulate the host transcriptome in their favour. In this review, we explore the literature that describes the epigenetic interaction of bacteria, fungi and viruses, with their mammalian hosts.
\end{abstract}

Keywords. Bacteria; DNA methylation; epigenetic modification; fungi; histone modifications; microbiota; ncRNA; viruses

\section{Introduction}

Coexistence in the same ecological niche promotes interactions between different organisms. Microbes form a dominant group of organisms who have formed a commensal or pathogenic relationship with the multicellular organisms with whom they coexist. Human microbiota, the microbes that coexist with humans, can be thought of as an additional multifunctional organ. In fact, the microbes that coexist with and within a human being outnumber the number of human cells by a factor of ten (Turnbaugh et al. 2007). The microbial cell can complement the metabolic traits, such as synthesis of specific vitamins, conjugated bile acid transformation, ability to break down complex plant polysaccharides, and dietary oxalate degradation. Microbiota educates our immune system to tolerate microbial immune determinants, reducing allergic response to environmental antigens, food, etc. (Xu and Gordon 2003).

The interaction of microbiota with its host has the ability to alter the cellular functions of both, through several mechanisms. Recent work, from many laboratories including our own, has shown that epigenetic mechanisms play an important role in the alteration of these cellular functions (Paschos and Allday 2010; Sharma et al. 2016). Epigenetics broadly refers to change in the phenotype without a corresponding change in the DNA sequence. This change is usually 
brought by epigenetic modifications of the DNA itself, the histone proteins associated with the DNA in the chromatin, non-coding RNA or the modifications of the transcribed RNA. These modifications, also known as epigenetic code, do not change the DNA sequence but alter the expression level of specific genes (Rothbart and Strahl 2014). Microorganisms seem to have learned how to modify the host epigenetic code and modulate the host transcriptome in their favour.

In this review, we explore the literature that describes the epigenetic interaction of bacteria, fungi and viruses, with their mammalian hosts.

\section{Epigenetic modifications}

\subsection{Histone modifications}

Post-translational modifications (PTMs) of histone proteins are known to alter chromatin organisation. Modifications decrease or increase the nucleosome compaction to form euchromatin (open chromatin conformation) or heterochromatin (closed chromatin conformation). Euchromatin is usually associated with active gene expression, whereas heterochromatin is normally associated with gene silencing. Modification of histones in their globular domain has the ability to influence histone-histone and histone-DNA interactions (Bannister and Kouzarides 2011). These modifications are established by the action of specific enzymes called epigenetic writers. Histone modifications are dynamic and protein factors called epigenetic erasers catalyse the removal of histone modifications. Thus an exceptional balance exists between these enzyme/enzyme complexes that determine the effective modifications present at a specific position on a particular histone (Jenuwein and Allis 2001; Bannister and Kouzarides 2011). Briefly described below (also see figure 1) are the different histone modifications known.

2.1.1 Acetylation: Histone acetyltransferases (HATs) acetylate the $\varepsilon$-amino group of lysine side chains on $\mathrm{H} 3$ and $\mathrm{H} 4$ using acetyl-CoA as a cofactor and histone deacetylases (HDACs) remove these acetyl groups (Roth et al. 2001). The acetyl group, being negatively charged is associated with the disruption of the electrostatic interactions, repulsion of the negatively charged DNA, and weakening of the histone-DNA interactions (Bannister and Kouzarides 2011). This allows open chromatin and active transcriptional state. Histone $\mathrm{H} 3$ acetyl lysine 9 (H3K9ac) and acetyl lysine 27 (H3K27ac) are associated with promoters and distal enhancers of transcriptionally active genes (Barnes et al. 2019). In addition to histone tails, acetylation also occurs at the globular domain of histones. Histone $\mathrm{H} 3$ acetyl lysine 56 (H3K56ac) in the histone $\mathrm{H} 3$ core protrudes its side chain towards DNA major groove affecting histone-DNA interactions (Yuan et al. 2009; Bannister and Kouzarides 2011).

2.1.2 Phosphorylation: Kinases, like KAT2A, phosphorylate the hydroxyl group of the amino acids Serine, Threonine, and Tyrosine using ATP as a phosphate group donor (Bannister and Kouzarides 2011). The addition of a phosphate group increases the net negative charge affecting the chromatin organisation. Phosphorylation influences the interaction between other histone modifications and is involved in chromatin condensation during mitosis. For instance, histone $\mathrm{H} 3$ phosphoserine 10 (H3S10ph) compacts chromatin during mitosis in all eukaryotes (Bannister and Kouzarides 2011; Rossetto et al. 2012). Similarly, histone H2B phosphoserine 14 condenses chromatin during apoptosis (Füllgrabe et al. 2010). Another example of regulation by histone phosphorylation is observed during double-stranded DNA breaks, where histone variant H2AX phosphoserine 139 (H2AXS139ph) recruits DNA damage repair proteins to the site (Lowndes and Toh 2005).

2.1.3 Methylation: Methyltransferases, like SETD7, catalyse the transfer of methyl group is transferred from S-adenosyl methionine (SAM), to $\varepsilon$-amino group on lysine and $\omega$-guanidino on arginine of histones. SET domain-containing enzymes (Lysine Methyltransferases, KMT) catalyse the transfer to lysine on histone tails (HKMTs), while non-SET domain containing proteins transfer methyl group to the globular domain (Greer and Shi 2012). Protein arginine methyltransferases (PRMT) family catalyses arginine methylation (Blanc and Richard 2017). Histone methylation can be stably propagated through multiple cell divisions. Unlike phosphorylation or acetylation, addition of methyl group allows maintenance of histone-DNA interactions. However, it is thought to influence the chromatin organisation due to the hydrophobicity of the methyl group. The count (mono-, di-, or tri-) and symmetry of methylation (symmetric, or asymmetric) increases the methylation complexity (Bannister and Kouzarides 2011). Methylation may participate in both, transcription activation or repression, depending on the site of methylation. Histone H3 methyl lysine 4 $(\mathrm{H} 3 \mathrm{~K} 4 \mathrm{me} 1 / 2 / 3)$ is enriched at gene promoters as well as transcription start sites of active and 
B

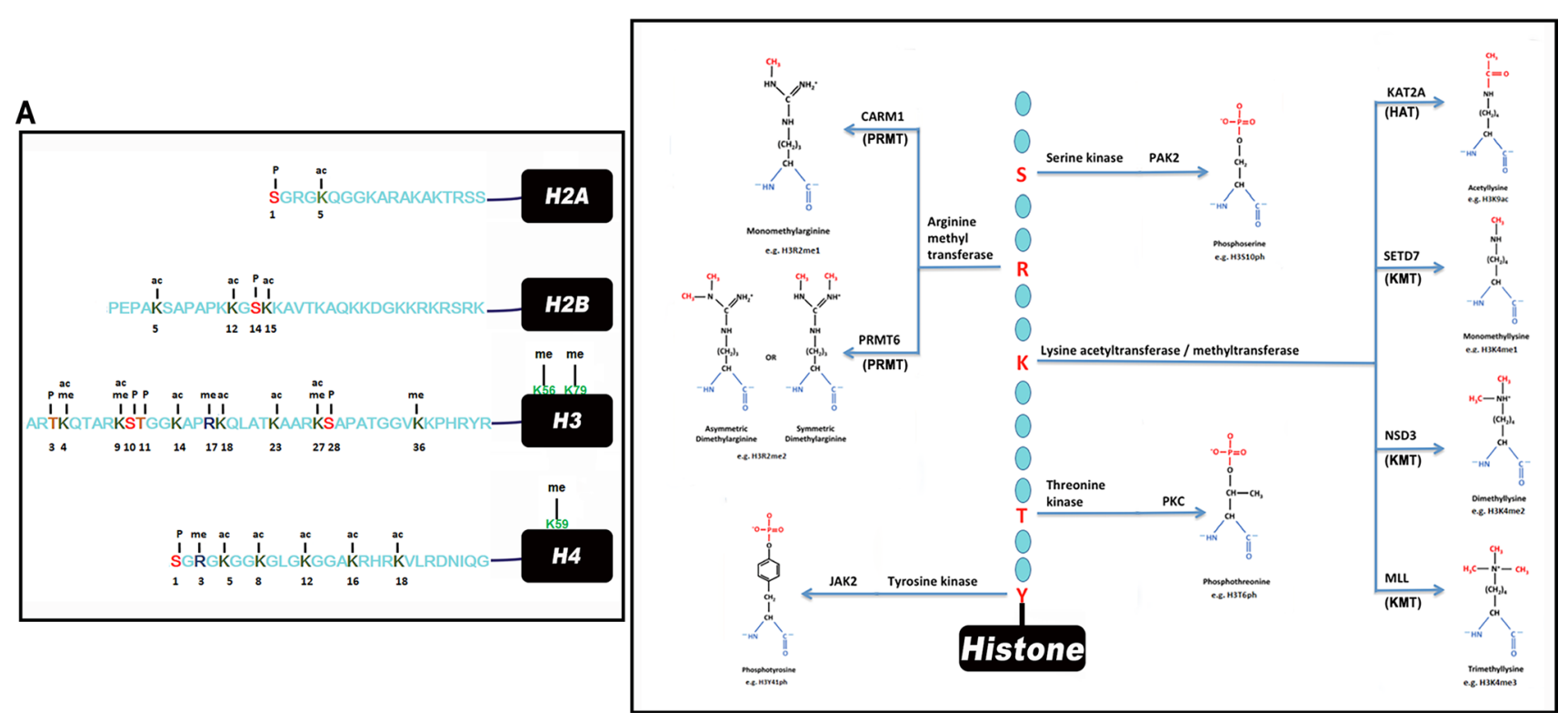

Figure 1. Histone post translational modifications (PTMs): Histone are modified at specific residues in their N-terminal tails (A) and by specific histone modifiers (B). (A) Summary of post-translationally modified amino acids in the various histone proteins. Globular core region of each histone is depicted by black rectangle. The amino acids in their N-terminal tails are depicted by 1-letter codes. PTMs are depicted above the 1-letter codes of amino acids. The numbers below depict the position of the modified amino acids from the N-terminus. The modified amino acids in the core regions of the histone are shown in green. Ac - acetylation, me-methylation, $\mathrm{P}$ - phosphorylation. (B) Changes in the molecular structure of amino acids by histone modifying enzymes. Acetylation: acetyl group added to terminal nitrogen atom in lysine by histone acetyltransferases (HATs). Phosphorylation: phosphate moiety is added to the hydroxyl group of $\alpha$-carbon in serine and threonine and to the para-hydroxyl group in tyrosine by kinases. Methylation: methyl group(s) is (are) added to the terminal amino group of lysine or arginine by lysine methyltransferases (KMTs) or protein arginine methyltransferases (PRMTs) respectively. Up to 3 methyl groups can be added to lysine (mono- or di- or trimethyl lysine). And 2 to arginine (mono- or di-methylarginine). The two methyl groups in dimethylarginine if added at the adjacent nitrogen atom forms symmetric dimethylarginine, whereas if added to same nitrogen atoms leads to asymmetric dimethylarginine. A few known examples of histone modifying enzymes are provided for each type of modifications.

developmentally-regulated genes. Histone $\mathrm{H} 3$ trimethyl lysine 36 (H3K36me3) is enriched on the gene bodies of transcribed regions (Greer and Shi 2012). On the other hand, histone $\mathrm{H} 3$ trimethyl lysine 9 (H3K9me3) is correlated with constitutive heterochromatin in genepoor regions such as repetitive elements present at centromeres, transposons, inactivated X-chromosome, etc. Histone H3 trimethyl lysine 27 (H3K27me3) temporarily marks gene-rich regions that regulate development and embryonic stem cell function. 'Bivalent domains' containing both H3K4me3 (active) and H3K27me3 (repressive) marks have been identified in pluripotent embryonic cells. These domains support low level of transcription (Greer and Shi 2012).

Arginine methylation is also associated with both activation and repression of a gene. Histone $\mathrm{H} 4$ asymmetric dimethyl arginine 3 (H4R3me2a) is associated with active transcription which recruits $\mathrm{H} 3 \mathrm{~K} 9 \mathrm{ac}$ for the binding of a transcription factor. Histone $\mathrm{H} 3$ asymmetric dimethyl arginine 17 (H3R17me2a) is also associated with active transcription. On the other hand, histone $\mathrm{H} 4$ symmetric dimethyl arginine 3 (H4R3me2s) and Histone H3 symmetric dimethyl arginine 8 (H3R8me2s) are associated with gene repression (Blanc and Richard 2017).

2.1.4 Ubiquitinylation: E1 (activation), E2 (conjugation), E3 (ligation) enzymes sequentially add covalent modifications on histones. Histone H2A monoubiquitinated lysine 119 (H2AK119ub1) and Histone H2B monoubiquitinated lysine 123 (H2BK123ub1) are associated with change in nucleosomal conformation and intranucleosomal interaction. It is also known to play a crucial role in the DNA damage response (Bannister and Kouzarides 2011; Cao and Yan 2012).

2.1.5 Tail clipping: Histone N-terminal's regulated proteolysis to remove multiple PTMs is known as tail 
clipping. It is reported in many organisms and is an irreversible process. It activate genes due to the increased DNA accessibility for transcription (SantosRosa et al. 2009; Bannister and Kouzarides 2011).

The histone modifications mentioned above, along with the deimination of arginine, O-linked $\beta$-N-acetyl glucosamination, ADP ribosylation, sumoylation, and proline isomerization constitute the 'Histone Code' (Turner 2002; Bannister and Kouzarides 2011). Proteins with specialised domains including chromodomain, tudor, MBT, bromodomain and PHD domain interact with and read the histone code to mediate binding of effector proteins to specific modifications and recruit the epigenetic machinery to alter chromatin organisation (Bannister and Kouzarides 2011; Rothbart and Strahl 2014). Furthermore, ATP-dependent nucleosome remodelling complexes containing these domains are known to mediate specific association with modified histones and their tails. For instance, the bromodomain of the SWI/SNF complex tethers to acetylated promoters, rearrange chromatin by assembling or disassembling nucleosomes and exchange histones with their variants (Becker and Workman 2013).

\subsection{DNA methylation}

DNA methylation is a reversible epigenetic modification of DNA and is associated with dynamic regulation of gene expression. Cytosine and Adenine bases in the DNA are known to be methylated in all organismsfrom bacteria to mammals (figure 2) (Blow et al. 2016; Greenberg and Bourc'his 2019).

2.2.1 $5 \mathrm{mC}$ methylation: Methylation of cytosine at the 5th position does not affect Watson-crick base pairing. However, despite being a small hydrophobic methyl group, it protrudes into the major groove of DNA affecting the biophysical properties (Pérez et al. 2012). Addition of this modification is catalysed by DNA methyltransferases. The de novo DNA methyltransferases DNMT3A and DNMT3B catalyse this addition on unmethylated DNA substrate (Okano et al. 1999). The maintenance methyltransferase, DNMT1, adds methyl group to hemimethylated DNA substrate and maintains DNA methylation through cell divisions ( $\mathrm{Li}$ et al. 1992). DNMT3L, which lacks catalytic activity, interacts with DNMT3A and DNMT3B and stimulates their activity besides recruiting them to the specific loci by binding to histone $\mathrm{H} 3$ that is methylated at lysine 4 (Bourc'his et al. 2001). De novo and maintenance methyltransferases collaborate to ensure DNA methylation is established and maintained in subsequent generations (Jaenisch and Bird 2003). DNMT2 or TRMT1 has also been classified as a DNA methyltransferase but it has been shown to methylate both tRNA and mRNA (Dev et al. 2017; Jeltsch et al. 2017). Ten-eleven translocation (TET) family proteins catalyse DNA demethylation actively by converting 5-methylcytosine to 5-hydroxymethylcytosine (Tahiliani et al. 2009). 5-hydroxy methylcytosine $(5 \mathrm{hmc})$ is an intermediate product - a new epigenetic mark that affects chromatin structure and gene expression (Shi et al. 2017).

DNA methyltransferases predominantly methylate cytosines in $\mathrm{CpG}$ dinucleotide context in the mammalian genome (Reik et al. 2001). CpG dinucleotides are present at frequency lower than expected in the genome and at most places as $\mathrm{CpG}$ islands (CGIs). These islands have been found near or within regulatory element and gene promoters (Deaton and Bird 2011). Gene promoters should be accessible to transcription factors and DNA methylation at these sites leads to transcriptional repression. Promoters of housekeeping genes are usually unmethylated (Reik et al. 2001). DNA methylation recruits methyl-CpG binding domain proteins including MeCP2, MBD1, MBD2, MBD3 and MBD4, which in turn engages histone deacetylases (HDACs) to repress transcription (Fournier et al. 2012). This cross-talk emphasizes the relationship between DNA methylation and histone modifications.

Non-CpG methylation is methylation of the cytosine in $\mathrm{CpA}, \mathrm{CpT}, \mathrm{CpC}$ dinucleotide context. First discovered in the plant genome (Lindroth et al. 2001), non$\mathrm{CpG}$ methylation is known to be catalysed by several DNA methyltransferases in mammals (Arand et al. 2012). Non-CpG methylation is highly enriched in neurons, glial cells, oocytes, ES cells and induced pluripotent stem cells (IPSCs). In adult somatic cells, non-CpG methylation accounts only for $0.02 \%$ of the total methylated cytosines. However, the level of nonCpG methylation is substantially more in ES cells (Laurent et al. 2010; Lister et al. 2011, 2013; Guo et al. 2014).

2.2.2 $N^{6}$-methyladenosine $(6 \mathrm{~mA})$ : Recent studies in mammals have shed light on N6-methyl adenine (6mA) (Heyn and Esteller 2015). Methylation of adenine at N-6 position was reported during the discovery of bacterial restriction-modification (R-M) system to protect against viral invasions (Arber and Linn 1969; Heyn and Esteller 2015). Extensive genomic analysis, 


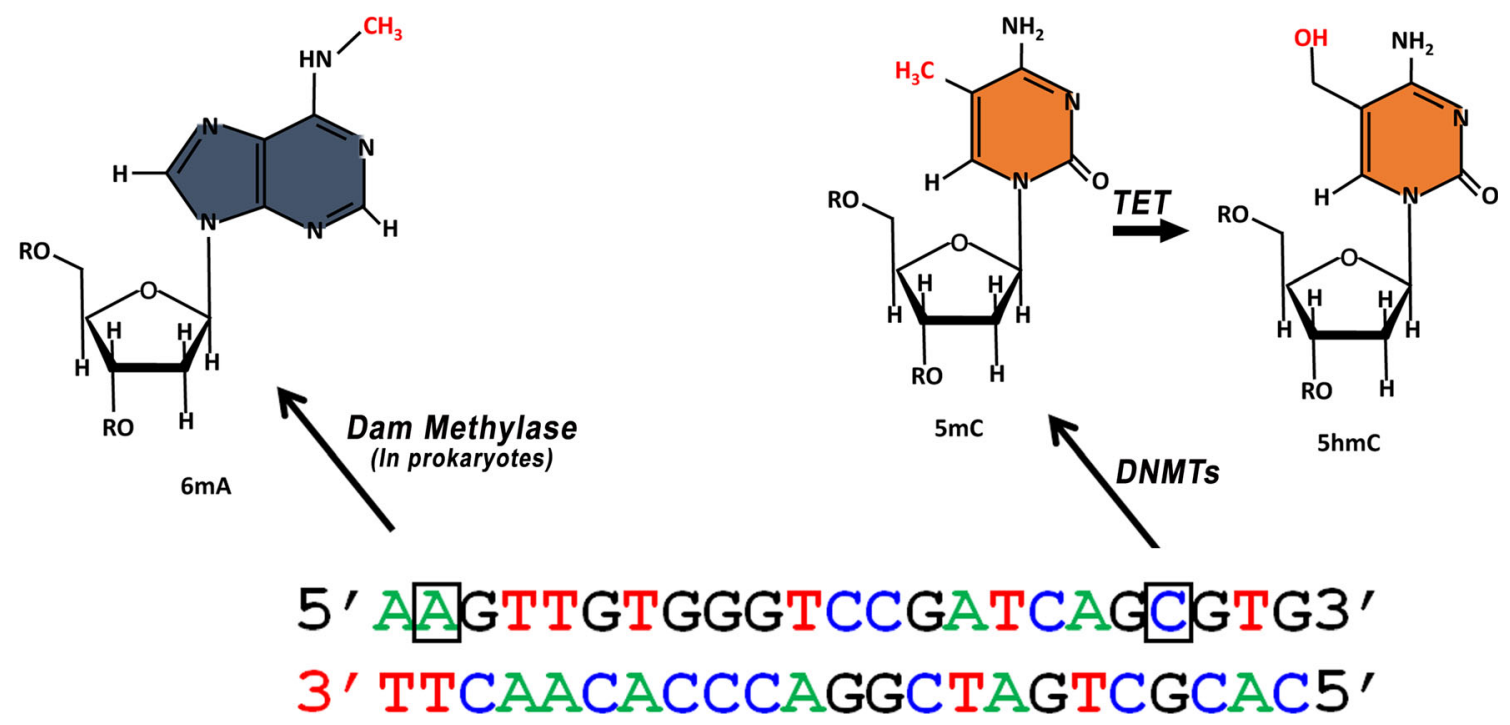

Figure 2. DNA methylation. Cytosine and Adenine methylation. Cytosine is methylated at the 5th carbon whereas Adenine is methylated at the 6 th carbon of the nitrogenous base. $\mathrm{m} 5 \mathrm{C}-5$-methylcytosine, hm5C -5 -hydroxymethylcytosine, m6 N6-Methyladenosine. A representative DNA sequence is provided. DNMTs -DNA methyltransferases; TET-an enzyme belonging to the hydroxy-methyltransferase family. Dam methylase- DNA adenine methyltransferase (known in prokaryotes).

reveals that eukaryotes (from fungus to mammals) during evolution have adopted adenine methyltransferases from prokaryotes. In different organisms, $6 \mathrm{~mA}$ is enriched in different genomic regions, including promoters, transcription start sites, coding regions, and transposons. Unlike cytosine, methylation of adenine upregulates transcription in most cases. $6 \mathrm{~mA}$ has been attributed with several functions that are speciesspecific (Fu et al. 2015; Zhang et al. 2015; Iyer et al. 2016; Koziol et al. 2016; Xiao et al. 2018).

DAMT-1, with a MTA70 domain, is a DNA adenine methyltransferase in C. elegans (Greer et al. 2015). RNA m6A methyltransferases, METTL3 and METTL14, are homologs in this family. METTL4, a DAMT-1 homolog in mammals, is a paralog of METTL3 and METTL14 (Balacco and Soller 2019).

\section{RNA modifications}

Several modifications of eukaryotic mRNAs are known: capping at the 5' end; polyadenylation at the 3' end, splicing to derive mature mRNA from pre-mRNA, etc. Recently, post-transcriptional modifications of cellular RNA (including non-coding RNA) similar to DNA and histone modifications have also been identified (Boccaletto et al. 2018). These modifications directly influence gene expression, adding another level of epigenetic regulation termed as 'epitranscriptomics'
(Saletore et al. 2012). Chemical modifications in RNA alter charge on transcripts, base-pairing potential, secondary structure, and protein-RNA interactions; these shape the outcome of gene expression by modulating RNA processing, localization, translation, and decay. Few of the common RNA modifications are shown in Figure 3.

\section{1 m6A methylation of RNA}

m6A is the predominant modification present on all cellular RNAs (Zaccara et al. 2019). meRIP-sequencing on human and mouse models reveal that m6A methylation is mainly enriched in long internal exons, 3' untranslated regions (UTRs), and region upstream of stop codon (Dominissini et al. 2012). A heterodimeric protein complex of METTL3 and METTL14 methylates RNA by depositing methyl group on exocyclic $\mathrm{NH} 2$ at the sixth position of the adenosine using SAM as a methyl donor (Figure 3, Liu et al. 2014). Proteins such as WTAP and KIAA1429 interact with the complex to load on to the target RNA (Ping et al. 2014). FTO and ALKB homologue 5 (ALKBH5) actively demethylate RNA m6A (Zheng et al. 2013; Mauer et al. 2017). m6A destabilizes RNA duplex to accommodate A-U bonding by rotating the methyl group from low energy syn (when unpaired) to high energy anti conformation (when paired with uracil). 


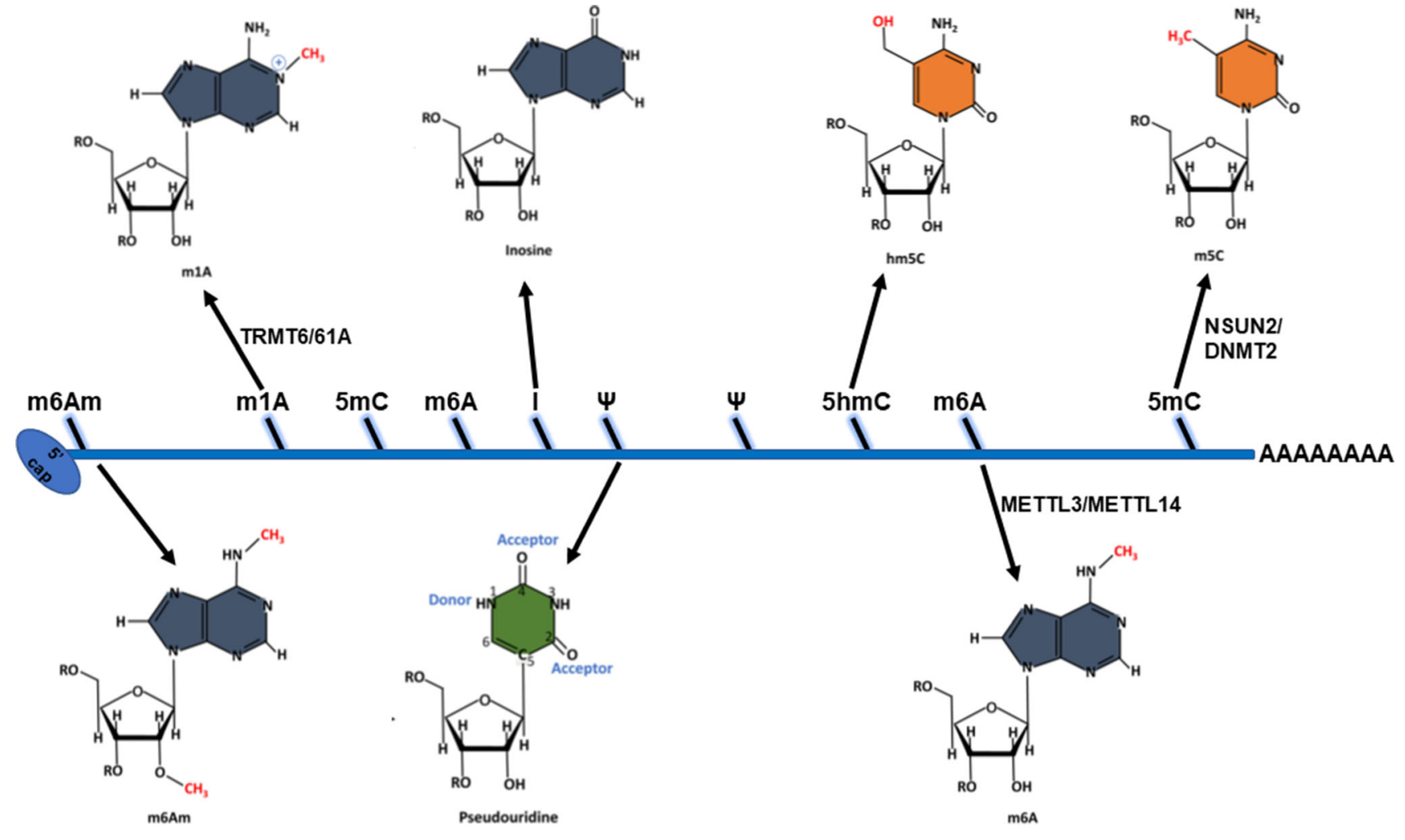

Figure 3. Modified RNA bases. Epigenetic modifications of mRNA or rRNA molecules. Methyl and hydroxyl group are added to the nitrogenous bases of either cytosines or adenine. m1A-N1-methyladenosine, m6A-N6-Methyladenosine, m6Am-N6,2-O-dimethyladenosine, m5C-5-methylcytosine, hm5C - 5-hydroxymethylcytosine, 2'-O-me-2'-O-Methylation, $\mathrm{CH} 3$ - methyl group, $\mathrm{OH}-\mathrm{Hydroxyl}$ group.

The rotation disrupts the local structure of transcripts predisposing it to bind to other proteins (Roost et al. 2015).

Reader proteins bind to $\mathrm{m} 6 \mathrm{~A}$ and decide the fate of target mRNA. YTH domain-containing proteins are a classic example for m6A readers: YTHDC1 (nuclear) affects mRNA splicing and export; YTHDC2 (nuclear and cytoplasmic) affects translation initiation and mRNA degradation; YTHDF1 (cytoplasmic) promotes translation; YTHDF2 (cytoplasmic) targets RNA to the P-bodies; YTHDF3 (cytoplasmic) binds to circular RNA. HNRNPC, HNRNPG, and HNRNPA2B1 preferentially bind to $\mathrm{m} 6 \mathrm{~A}$ in non-coding RNA (Xiao et al. 2016; Hsu et al. 2017; Zaccara et al. 2019).

\subsection{N1-methyladenosine}

N1-methyladenosine (m1A) refers to methylation at the $\mathrm{N} 1$ position of adenosine. m1A blocks base-pairing at the Watson-Crick interface, unlike m6A and other adenosine methylations, affecting the RNA secondary structure and protein-RNA interactions (Dominissini et al. 2016; Roundtree et al. 2017). tRNA and rRNA abound with m1A. m1A correlates with the upregulation of translation due to its unique position near translation start sites and the first splice site of the coding transcripts. ALKBH3 demethylates $\mathrm{m} 1 \mathrm{~A}$ in response to cellular stresses (Dominissini et al. 2016; Roundtree et al. 2017).

\subsection{5-methylcytosine}

RNA methyltransferases NSUN2 and DNMT2 methylate RNA at the fifth position of cytosine $(5 \mathrm{mC})$ (Goll et al. 2006; Hussain et al. 2013; Dev et al. 2017). Several findings have revealed that $5 \mathrm{mC}$ distributes on precise mRNA regions and, $5^{\prime}$ and $3^{\prime}$ UTRs, a binding site for argonaute proteins (Squires et al. 2012). $5 \mathrm{mC}$ stabilizes RNA structures by promoting base stacking leading to the increased thermal stability of hydrogen bonding with guanosine. $5 \mathrm{mC}$ stabilized tRNAs influence the anti-codon stem-loop conformation and translational fidelity of rRNA. ALYREF, an mRNA export adaptor protein, recognizes and exports $\mathrm{m} 5 \mathrm{C}$ 
transcripts (Squires and Preiss 2010; Roundtree et al. 2017).

\subsection{2'-OH methylation}

2'-OH methylation of ribose is frequent in RNAs. In piRNA, 2'-O-me is vital for its recognition by PiwiClaude argonautes over Ago-Claude proteins. 2'-O-me affects secondary structures of RNA and their interactions with proteins. $2^{\prime}-\mathrm{O}-\mathrm{me}$ exists in the second and third nucleotides, which may also have adenosines methylated at the sixth position, and together they form m6Am modification and rescue mRNA from degradation (Kurth and Mochizuki 2009; Roundtree et al. 2017).

\subsection{Pseudo uridine}

Uridine can isomerize to give the fifth nucleotidepseudo uridine ( $\Psi) . \Psi$ provides an additional hydrogen bond donor, helps in the proper folding of rRNA, and stabilizes the $\mathrm{C}-\mathrm{C}$ bond and tRNA structure (Roundtree et al. 2017).

\subsection{Adenosine-to-Inosine RNA editing}

Adenosine deaminases acting on RNA (ADARs) deaminates adenosine to inosine, which pairs with cytosine. A-to-I editing recodes the transcript by pairing inosine non-canonically with guanosine, altering protein sequences, and affecting splicing and miRNA biogenesis (Bass 2002; Roundtree et al. 2017).

\section{Non-coding RNA}

Genome-wide deep sequencing studies reveal that mammalian transcriptomes are only partially translated into proteins; studies estimate that 80,000 out of 100,000 RNAs remain untranslated and are known as non-coding RNAs. They are divided mainly into two classes based on length as long non-coding RNA (>200nt) and short non-coding RNA ( $<200 \mathrm{nt})$. Noncoding RNAs influence gene expression at both transcriptional and post-transcriptional levels. As genome complexity evolved across organisms, non-coding RNA count correspondingly increased with number of protein-coding genes remaining relatively static (Derrien et al. 2012).

\subsection{Long non-coding (long ncRNA) RNA}

Long ncRNAs recruit chromatin-remodeling complexes. The components of PRC1 and PRC2 chromatin remodelling complexes, which establish repressive histone mark H3K27me3, interact with ncRNA. For example, Xist, a long ncRNA, expresses from $\mathrm{X}$-chromosome and binds to $\mathrm{PRC} 1$ and $\mathrm{PRC} 2$ protein complexes, establishes $\mathrm{H} 3 \mathrm{~K} 27 \mathrm{me} 3$ and also recruits histone deacetylases and DNMT3A to methylate $\mathrm{CpG}$ (Ponting et al. 2009; Derrien et al. 2012).

\subsection{Small non-coding $R N A$}

Small non-coding RNAs are either structural (ribosomal, transfer, small nuclear, small nucleolar RNAs) or regulatory (miRNA, siRNA, piRNA) in nature. Small non-coding RNAs mediate post-transcriptional interference - a powerful mechanism for gene silencing. miRNAs are evolutionarily conserved 20 to 24 nucleotides single-stranded RNA molecules. Mature miRNAs are processed from imperfectly paired hairpin pre-precursor miRNA by the action of Drosha and Dicer. Mature miRNA interacts with Argonaute (Ago) proteins to form the RNA-induced silencing complex (RISC) and targets $3^{\prime}$ UTRs to guide gene silencing. siRNAs are similar to miRNA in size and function. However, Dicer processes the mature siRNA from a long, linear dsRNA precursor. Processed siRNA is loaded onto RISC, which degrades the target mRNA. siRNAs are thought to be protecting the genome from invasion by viruses and transposons (Krol et al. 2010). piRNAs vary from 24 to 31 nucleotides and contain uridine at the $5^{\prime}$ end, and $2^{\prime}$-O-methylation at the $3^{\prime}$ end. piRNAs get their name from Piwi proteins of the Argonaute family that process the single-stranded precursor to anti-sense RNAs. The primary role of piRNA is to cleave transposons and protect the germline, which generates sense piRNAs arising from the target transposons. The anti-sense and sense piRNAs enter into a 'Ping-Pong' cycle increasing the piRNA pool (Czech and Hannon 2016).

RNA-induced silencing complexes (RISCs) is a versatile gene-silencing machine that contains a complex of different proteins. RISC co-localizes with target RNAs and generates gene-silencing pathways. RISC can repress protein synthesis, degrade target RNA, and establish heterochromatin. The RISC core is composed of two modules: (i) a small regulatory RNA such as siRNA, miRNA, piRNA, rasiRNA, tasiRNA, tncRNA, hcRNA, scnRNA which function as a guide by 
establishing Watson-Crick base pairing with their targets and (ii) a highly conserved argonaute protein bound to the small RNA along with associated proteins. The exact composition of the RISC complex varies with different determinants like associated RNA type, the function, and the subcellular location (Paroo et al. 2007).

\section{Microbial interaction with the host epigenetic machinery}

Host mammalian cells interact with several types of microbes including bacteria, viruses, fungi, protozoa, etc. Microbial interaction could be intracellular or extracellular. It could be binary (one host, one microbe), or consortia (Eloe-Fadrosh and Rasko 2013). The interaction could be commensal or pathogenic. Presented below is a brief review of literature which describes modulation of the host epigenetic circuitry by microbes.

\subsection{Bacteria and the host epigenetic circuitry}

Bacterial factors can modify DNA by incorporating foreign genetic material into the genome, alter the availability of chemical donors for modifying histone or DNA by producing metabolites, and directly interact with the host modifying enzymes such as HMTs, HDACs, and DNMTs. Pathogenic as well as commensals, can modulate the host epigenetic machinery for their survival. They have an array of epigenetic modifiers that follow different modes of action; interact with the target receptor leading to a signalling cascade, target an intracellular host protein to mediate a modified signalling cascade or self-modify the target host protein directly (Cortese et al. 2016). In the following section, we discuss the available literature on the epigenetic interaction of the various bacterial species that are known to have a symbiotic or pathogenic relationship with humans. The summary of bacterial mode of interaction with host epigenetic machinery is summarized in table 1.

5.1.1 Bacteroides: Bacteroides (gram-negative, bile resistant, anaerobic and non-spore forming) form one of the earliest arising lineages of bacteria in a human infant, bacteria which the mother passes to the child during birth. Bacteroides are commensal until they escape from the gut due to GI tract rupture or surgery. Outside the gut they may cause abscess formation in various parts of the body, including the brain, pelvis, lungs, abdomen, and liver (Wexler 2007). B. vulgatus has been shown to induce inflammatory signalling cascade leading to phosphorylation and acetylation of histone H3. Studies have shown that it can maintain homeostasis via TGF $\beta 1 /$ Smad signalling and by regulating NF-kB signalling in the intestinal epithelium through reduction in $\mathrm{H} 3$ acetylation levels and recruitment of HDAC at pro-inflammatory gene promoters.

Metabolites sulforaphane cysteine and sulforaphane $\mathrm{N}$-acetyl-cysteine from cruciferous vegetables and allyl mercaptan and diallyl disulfide from garlic by $B$. thetaiotaomicron are potent histone deacetyltransferase inhibitors (Haller et al. 2003; Bhat and Kapila 2017). Epigenetic modifications have also been identified in the genome of $B$. dorei during metagenomic analysis of stool samples. The study indicated the presence of m6A methylation at 20,551 GATC sites within the bacterial genome distributed over the gene body as well as intergenic regions. The study also highlighted methylation of the Ton and Tol transport system, an energy source for transporting across the outer membranes in gram-negative bacteria (Leonard et alet al. 2014).

5.1.2 Bifidobacterium: Bifidobacterium is one of the earliest microbes that colonizes the gut of an infant. It is amongst the various bacteria that are part of probiotics, nutraceuticals, and dairy products. Bifidobacteria genomic DNA has high $\mathrm{G}+\mathrm{C}$ content. Studies have shown that unmethylated $\mathrm{CpG}$ motifs from the bifidobacterial genome interact with TLR9 (Toll-like Receptor-9) present on immune cells promoting $T_{h} 1$ response, which fights against intracellular viral pathogens.

Lack of folate or the methyl group (from SAM) in the diet is associated with DNA hypo-methylation in rats and humans. Folate abundance affects the efficiency of DNA methylation, repair, and replication. Bifidobacterium strains are known to produce folate. One of the Bifidobacterium strains BGN4 is also known to produce S-Adenosyl-L-methionine (SAM), a methyl donor and a substrate for methylation reaction (Pompei et al. 2007; Ruiz et al. 2017). In addition, B. breve has been shown to reduce global histone $\mathrm{H} 4$ and $\mathrm{H} 3 \mathrm{~S} 10 / \mathrm{K} 14$ acetylation and increases DNA methylation in HT29 cells (Ghadimi et al. 2012).

\subsubsection{Faecalibacterium: Bacteria of Faecalibacterium} species belongs to the phylum firmicutes. F. prausnitzii is an oxygen-sensitive, spore-forming gut commensal, 


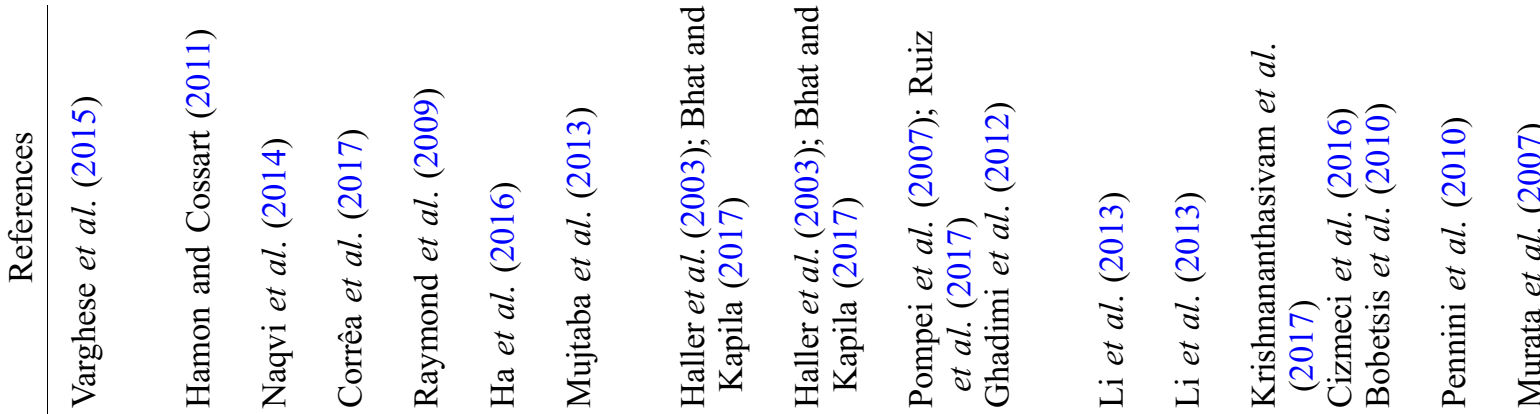

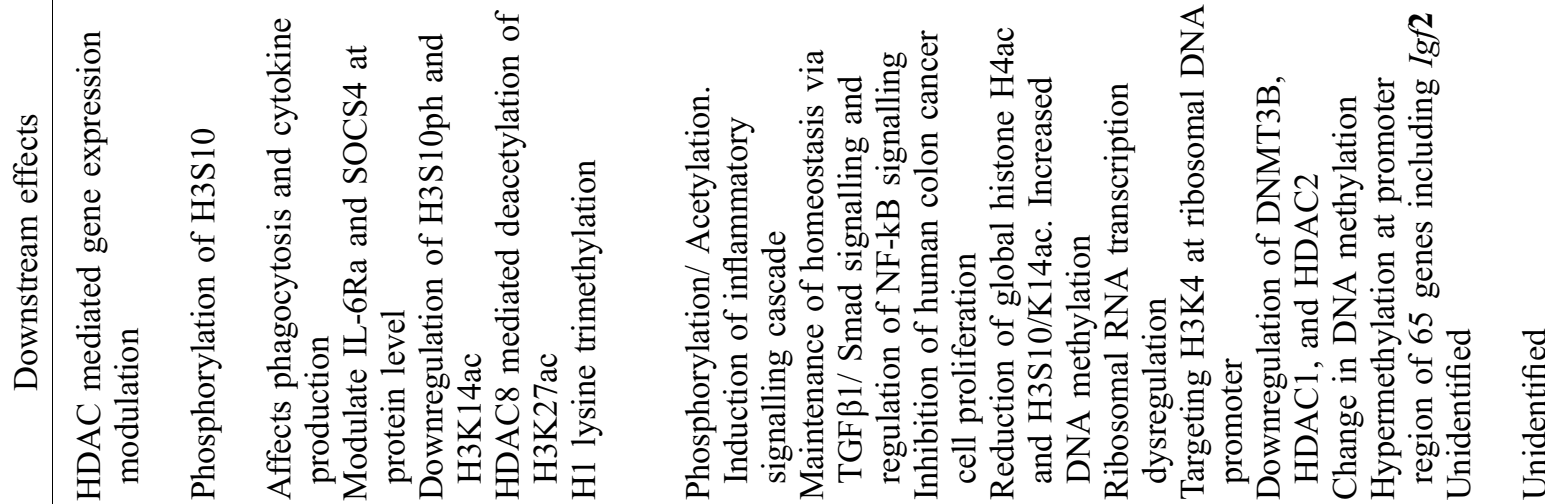

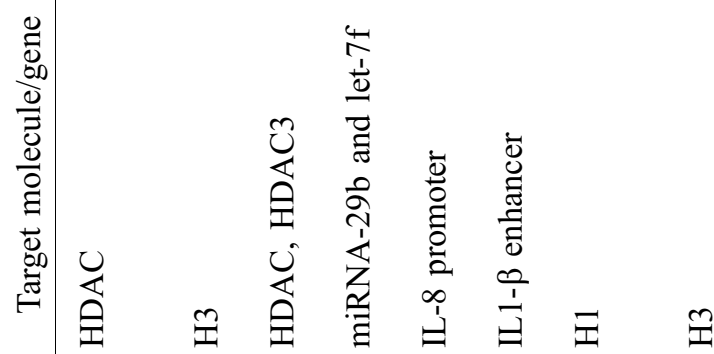

基

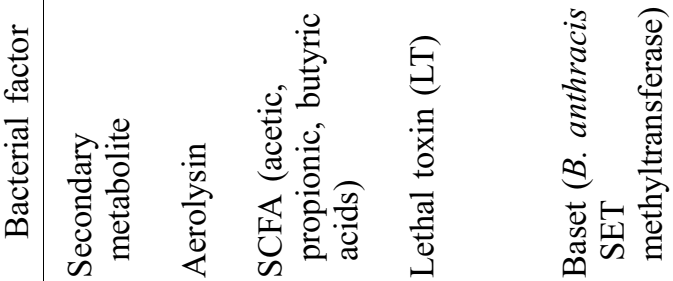

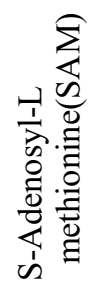

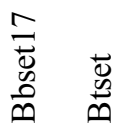

苛

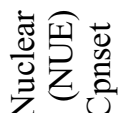

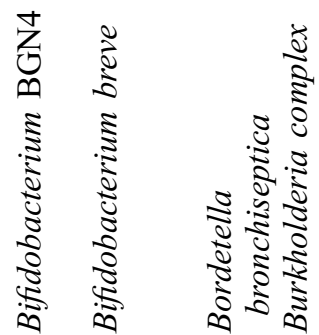




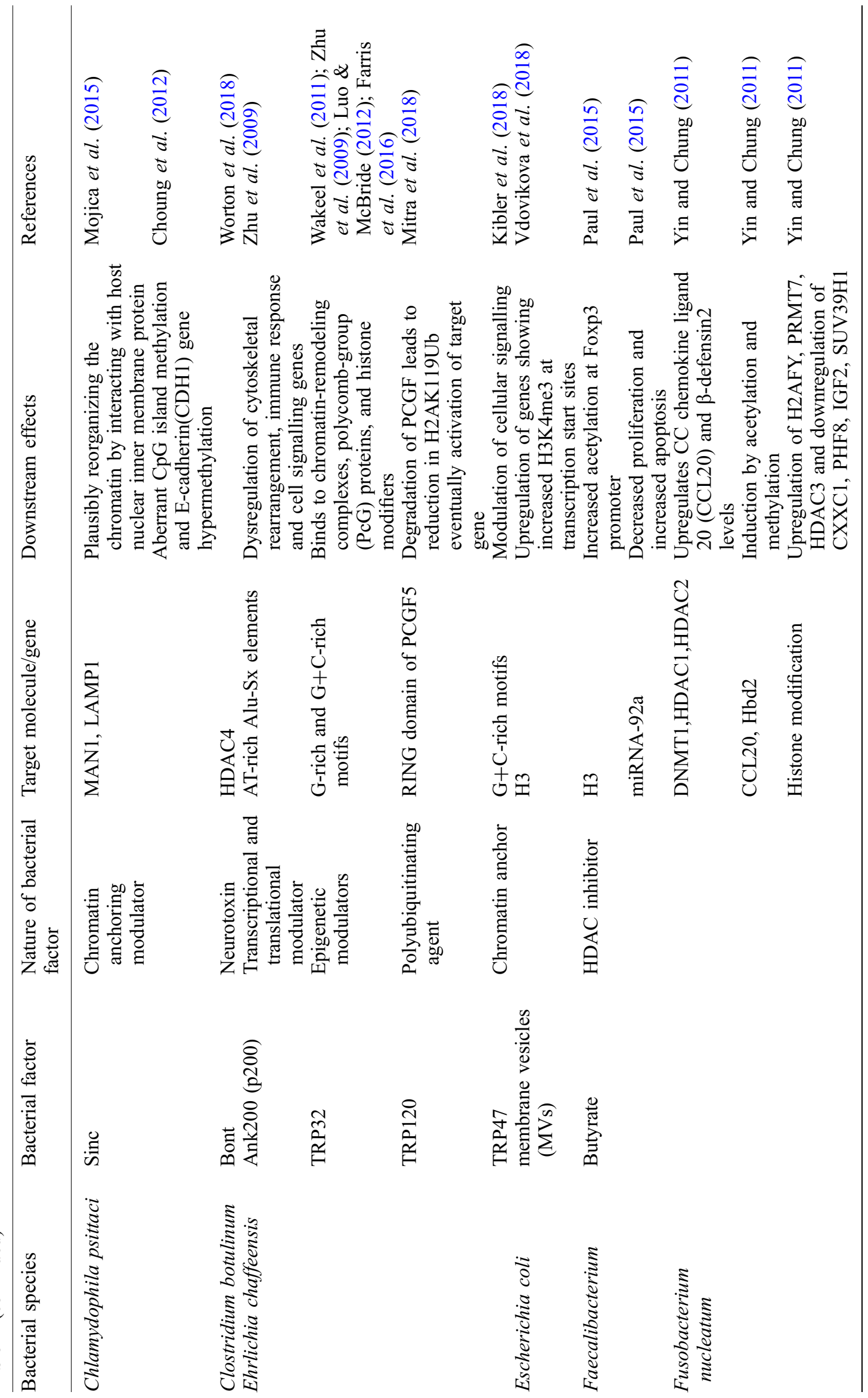




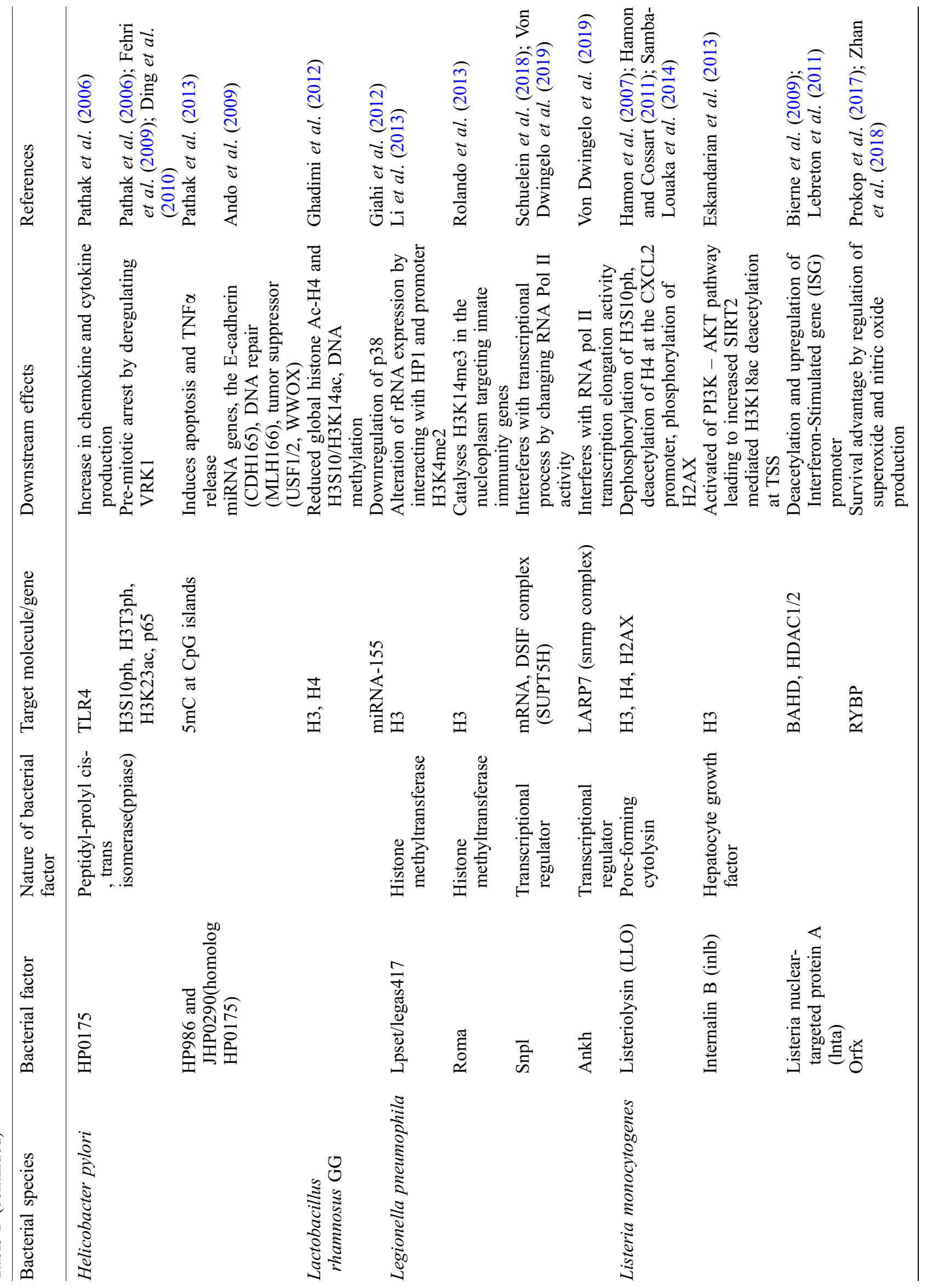




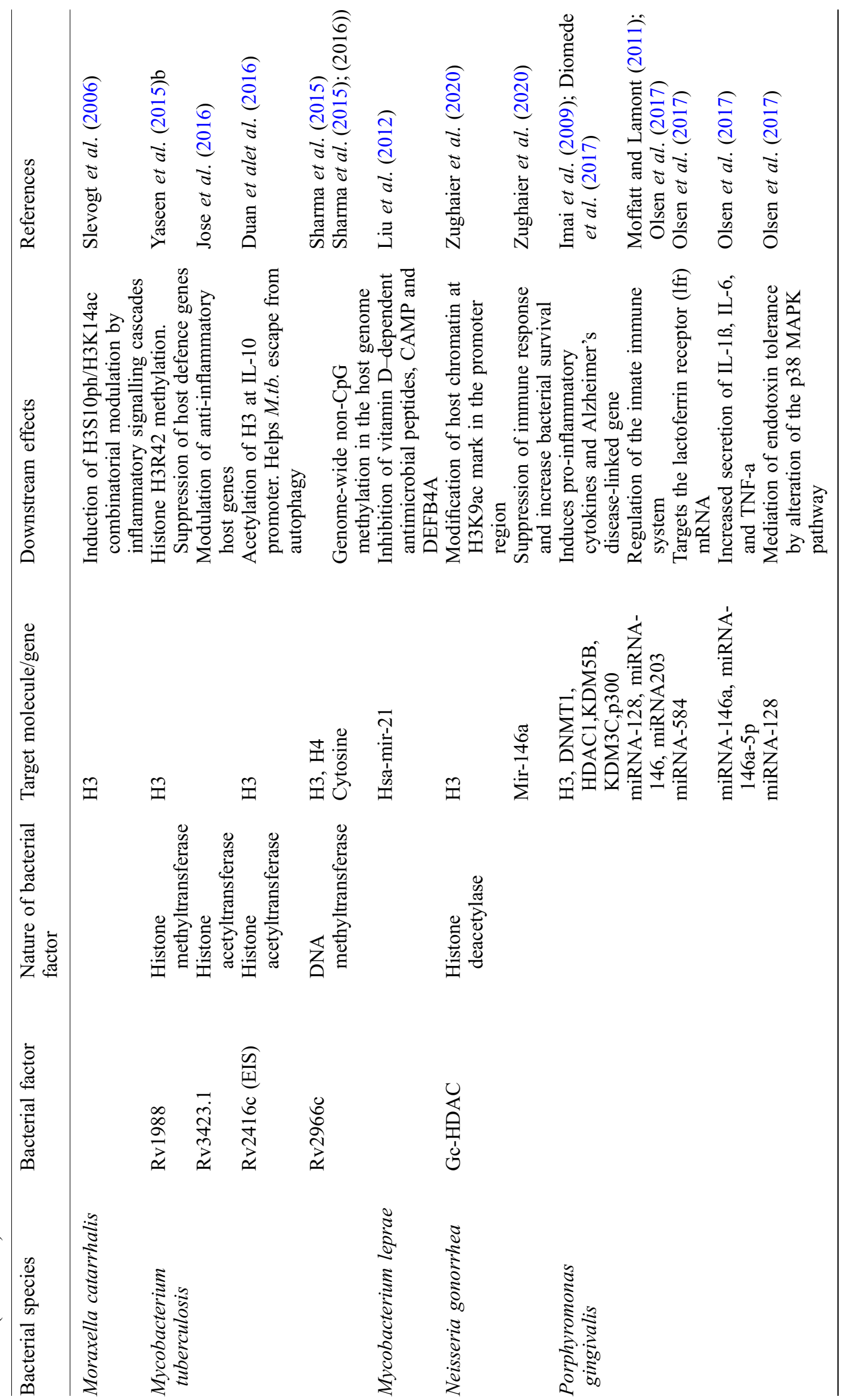




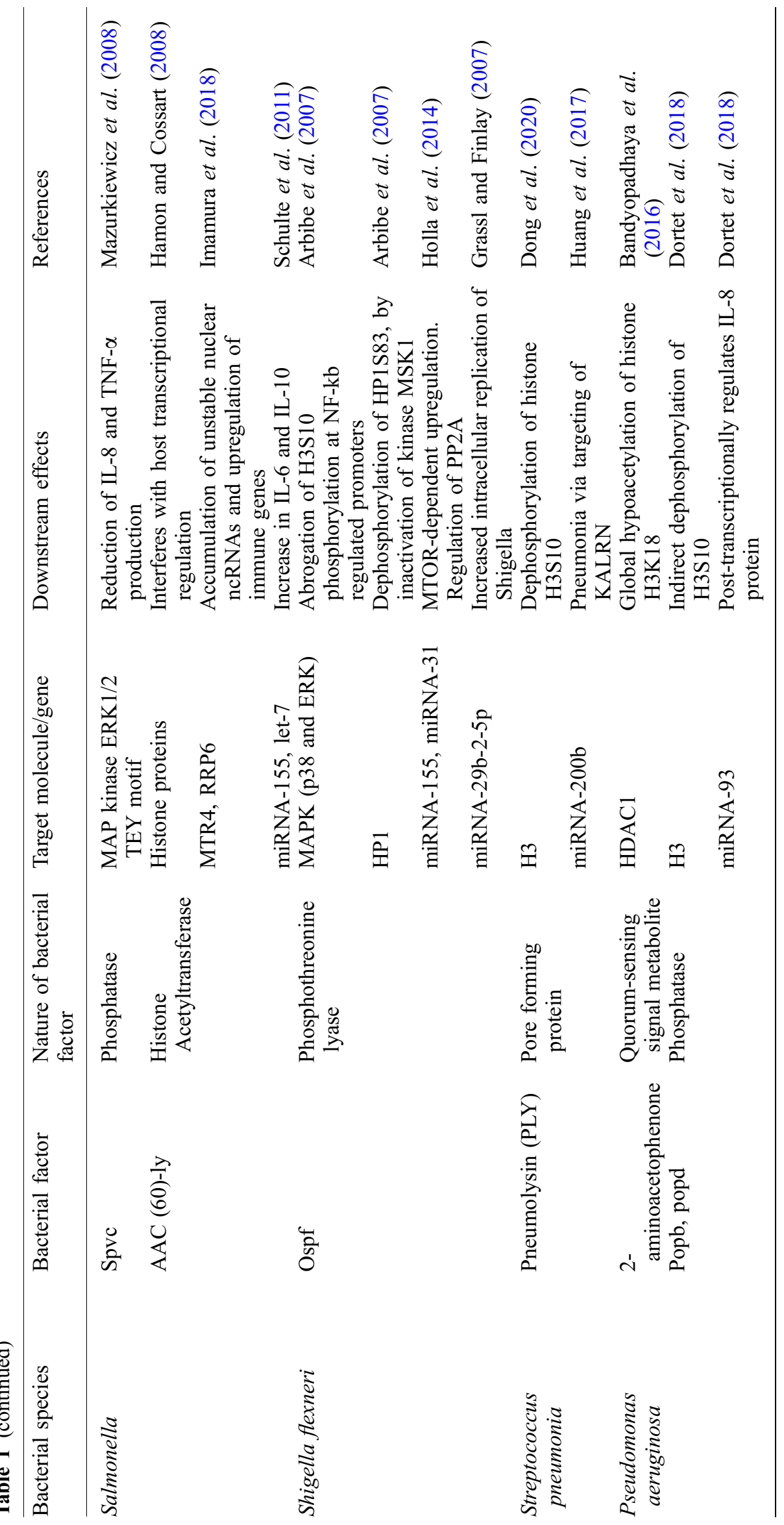


and has been considered as a marker of health because of its low abundance in Inflammatory Bowel Disease (IBD). It secretes factors that cause immunomodulation, inhibition of NF-kB activation and IL-1 $\beta$ mediated IL-8 secretion in Caco-2 cells (Miquel et al. 2013). Studies have uncovered that mothers having higher levels of firmicutes show hyper-methylation of promoters of 568 genes and hypo-methylation of promoters of 245 genes (Kumar et al. 2014).

Faecalibacterium produces butyrate in the gut, which constitutes a preferred energy source for colonic epithelial cells. Butyrate is a short-chain fatty acid (SCFA) rapidly absorbed by the lumen of the colon and is a recognized HDAC inhibitor. Butyrate induces colonic Treg cell differentiation by increasing the level of histone $\mathrm{H} 3$ acetylation at the promoter and conserved regions of Foxp3 and functions as a tumour suppressor against colonic cancer by decreasing proliferation and increasing apoptosis through inhibition of miR-92a transcripts. Butyrate also derepresses epigenetically silenced genes (such as p21 and BAK) in cancer cells (Paul et al. 2015).

5.1.4 Lactobacillus: Lactobacilli are members of lactic acid bacteria (LAB) family, characterized by their carbohydrate metabolism leading to lactic acid production. These bacteria are commonly used as probiotics since they can colonize the oral cavity, GI tract, and vagina in humans as well as other mammals (Walter 2008). Exposure to Lactobacillus spp. (singly or in combination with $E$. coli) reduces global histone $\mathrm{H} 3$ and $\mathrm{H} 4$ acetylation levels in colonic cancer cell line Caco2. Global DNA methylation levels remain unaffected when Caco2 cells are exposed to Lactobacillus spp. alone but in combination with $E$. coli the level show significant alteration (Bhat et al. 2019). Co-incubation of $L$. rhamnosus GG increases global DNA methylation and reduces histone $\mathrm{H} 4$ and $\mathrm{H} 3 \mathrm{Ser} 10$ / Lys14 acetylation in HT29 cells (Ghadimi et al. 2012). This co-incubation also leads to downregulation of $\mathrm{p} 38$ by upregulation of miR-155 (Giahi et al. 2012). Coincubation with $L$. acidophilus enhances the expression of genes that are silenced in colorectal cancer (CRC) by DNA methylation (Icam5, Clstn2, Ppmle, Runx3, Timp3, Rgl1, and Rassfla) (Lightfoot et al. 2013).

Among vaginal commensals, $L$. gasseri and $L$. reuteri have been shown to modulate the gene expression of the $D E F B 1$ (Defensin Beta-1) gene, which encodes for antimicrobial peptide human $\beta$-defensin-1. In vaginal keratinocyte cells $\mathrm{VK} 2 / \mathrm{E} 6 \mathrm{E} 7$, this modulation is bacterial species dependent; $L$. gasseri causes enrichment of $\mathrm{H} 3 \mathrm{~K} 4 \mathrm{me} 3$ and acetylation of $\mathrm{H} 3$ at the promoters with increased DEFB1 expression but $L$. reuteri shows an opposite effect (Lee et al. 2017). Lactate produced by Lactic acid bacteria inhibits HDAC and enhances HDAC associated gene expression but is not as proficient as trichostatin and butyrate (Latham et al. 2012). In mouse model, L. plantarum was shown to induce differential methylation of transcripts involved in cellular function and maintenance, cellular assembly, and vitamin metabolism (Jabs et al. 2020).

\subsubsection{Fusobacterium: Fusobacterium is a typical oral} microbiota and has symbiotic relationship with the human. However, it is also an opportunistic pathogen and may cause colorectal cancer (Brennan and Garrett 2019). F. nucelatum has been shown to epigenetically lower the gene expression of DNMT1 and HDAC2 in gingival epithelial cells (GEC) as well as human immortalized keratinocyte cell lines (TERT). F. nucelatum can induce CCL20 and $h B D \mathbf{2}$ expression in the oral cavity by acetylation and methylation. It has also been shown to cause hypomethylation of Elastase 2 and GATA3 genes and hypermethylation of MALT1 gene. In addition, co-incubation with Fusobacterium affects the expression of genes involved in epigenetic modifications. It downregulates histone $H 2 A F Y$, HELLS (helicase implicated in chromatin remodelling), PRMT7, and $H D A C \mathbf{3}$ and upregulates $C X X C \mathbf{1}, P H F \mathbf{8}, I G F \mathbf{2}$, SUV39H1, and CARM1 (Yin and Chung 2011).

5.1.6 Escherichia coli: E. coli is a prominent inhabitant of the gut microflora. It is a commensal and helps to maintain gut homeostasis, but transforms into pathogenic strain upon acquiring chromosomal or extrachromosomal virulence operons (Duriez et al. 2001). Pathogenic E. coli causes urinary tract infections (UroPathogenic E. coli-UPEC), diarrhoea in young children (EnteroPathogenic E. coli-EPEC), and haemolytic uremic syndrome (EnteroHemorrhagic $E$. coli-EHEC). Uropathogenic $E$. coli has been shown to cause changes in histone acetylation and DNA methylation in the host during infections (Tolg et al. 2011). Commensal E. coli interacts with host epigenetic machinery via the production of membrane vesicles (MVs). Upon exposure of HCT8 cell line to commensal E. coli MVs, upregulation of 738 out of 1434 differentially expressed genes was observed. H3K4me3 increased at the transcription start site (TSS) of the upregulated genes. Also, MVs remodelled chromosomes by opening chromatin or relaxing chromosome at TSS of upregulated genes leading to increased accessibility of nucleosome-free DNA to the transcription machinery (Vdovikova et al. 2018). 
5.1.7 Anaplasma phagocytophilum: Anaplasma phagocytophilum is a tick-transmitted obligate intracellular rickettsial pathogen that causes human granulocytic anaplasmosis. Bacteria of this species abrogate essential antimicrobial functions of the host cell to survive inside the hostile environment of neutrophils by replicating within vacuoles and secreting effectors through a bacterial type IV secretion system (T4SS) (Borjesson et al. 2005). One such effector is AnkA, which contains ankyrin (Ank) repeats usually found in eukaryotic nuclear transcription factors (Garcia-Garcia et al. 2009). AnkA binds to the AT-rich promoter of $C Y B B$ gene in the granulocyte nucleus recruiting HDAC1 and leading to the deacetylation of H3 (Rennoll-Bankert et al. 2015). The reprogramming represses CYBB encoded $\beta$-subunit of NOX2, which mediates superoxide anion production. The superoxide deprivation abolishes a critical mechanism of bacterial elimination from infected neutrophils and presents the pathogen a significant survival advantage. AnkA is also known to target other AT-rich sites, at various chromosomal locations and associated with nuclear protein matrix attachment regions (MARs), and changing the 3D structure of the chromatin by directing chromosomal remodeling dynamics (Dumler et al. 2016).

5.1.8 Bacillus anthracis: Bacillus anthracis is an anthrax causing endospore-forming bacterium that produces a lethal toxin (LT) which disrupts MAPK signalling by inactivating MAPKKs (Bardwell et al. 2004). LT-mediated inhibition downregulates H3S10ph and $\mathrm{H} 3 \mathrm{~K} 14 \mathrm{ac}$ at IL-8 promoter in lung epithelial cells and deacetylates HDAC8 mediated H3K27ac at IL1- $\beta$ enhancer in macrophages (Ha et al. 2016). B. anthracis also produces a Lysine methyltransferase (BaSET) that enters the nuclei and carries out H1 lysine trimethylation upon infection in macrophages (Mujtaba et al. 2013).

5.1.9 Burkholderia complex: Members of Burkholderia complex including $B$. pseudomallei and $B$. thailandensis cause human melioidosis. Although nonpathogenic, B. thailandensis infections in human are reported. They also produce a Lysine methyltransferase, BtSET that targets $\mathrm{H} 3 \mathrm{~K} 4$. BtSET associates with ribosomal DNA promoters during in vitro ectopic expression in cell lines (Li et al. 2013). In addition, aberrant DNA methylation has been observed at genomic loci associated with pathogen-induced signalling, intracellular signalling, inflammatory responses, and apoptosis during $B$. pseudomallei infection (Cizmeci et al. 2016). Furthermore, B. thailandensis infection has been shown to cause significant downregulation of $D N M T 3 B, H D A C \mathbf{1}$, and $H D A C 2$ (Krishnananthasivam et al. 2017).

5.1.10 Chlamydia: Chlamydia trachomatis causes a wide assortment of diseases such as trachoma (eye infection), inflammation of the urethra and pelvis, ectopic pregnancy, neonatal infections, and lymphogranuloma venereum, a sexually transmitted disease. It has been shown to secrete a nuclear effector (NUE), which is a SET domain harbouring histone methyltransferase that can methylate host histones H2B, H3, and H4 (Pennini et al. 2010). Chlamydophila pneumoniae, which causes pharyngitis, bronchitis, and atypical pneumonia in humans, encodes a SET domain protein cpnSET that can methylate histone H3 (Murata et al. 2007).

Chlamydophila psittaci, which causes pneumonia (systemic infection) as well as psittacosis or ornithosis (latent and persistent infection), is associated with ocular adnexal marginal zone B-cell lymphoma (OAMZL) in humans. Aberrant $\mathrm{CpG}$ island methylation and E-cadherin (CDH1) gene hypermethylation are characteristic of OAMZL (Choung et al. 2012). C. psittaci also secretes SinC, a chromatin-anchoring modulator that targets host nuclear inner membrane proteins such as MAN1 and LAMP1 and is correlated with the reorganization of the chromatin (Mojica et al. 2015).

5.1.11 Ehrlichia chaffeensis: Ehrlichia chaffeensis, a tick-transmitted rickettsial pathogen causes human monocytotropic ehrlichiosis. This pathogen reprograms the mononuclear phagocyte landscape by secreting bacterial type I secretion system (T1SS) effectors, namely Ank200 (p200), tandem repeat containing protein (TRP) 32, TRP47 and TRP120 (Wakeel et al. 2011). p200 binds to chromatin at ATrich regions termed as Alu-Sx elements and targets a wide array of genes involved in intracellular trafficking, cytoskeletal rearrangement genes, immune response, cell signalling and transcriptional/translational regulation, leading to substantial dysregulation of the host cellular environment (Zhu et al. 2009). The serine-rich TRPs, TRP32 and TRP120 bind to G-rich and G+C-rich motifs in the host DNA, respectively. They also bind to epigenetic modulators such as chromatin-remodelling complexes, polycombgroup (PcG) proteins, and histone modifiers (Luo et al. 2011). TRP120 interacts with the RING domain of PCGF5, a PRC1-like complex component through a C-terminal HECT E3 domain, to target PCGF for 
polyubiquitination (Dunphy et al. 2014). The degradation of PCGF concurs with a reduction in histone $\mathrm{H} 2 \mathrm{~A}$ ubiquitinated at lysine 119 , leading to transcriptional activation of the target genes. TRP47 harbours an MYND-binding domain and translocates to the nucleus and binds to $\mathrm{G}+\mathrm{C}$-rich motifs (Kibler et al. 2018). TRPs redundantly target transcriptional regulation, signal transduction, apoptosis, immune cell differentiation, chromatin remodelling, and RNA transcription genes (Farris et al. 2016).

5.1.12 Helicobacter pylori: Helicobacter pylori can invade gastric epithelial cells and survive in mononuclear phagocytes and neutrophils by disrupting phagosome maturation. H. pylori secrete HP0175, a peptidyl-prolyl cis-, trans isomerase (PPIase), which activates IL-6 promoter leading to MAP kinases mediated MSK1 phosphorylation that in turn transiently dephosphorylates H3S10ph and H3T3ph, reduces $\mathrm{H} 3 \mathrm{~K} 23 \mathrm{ac}$ and $\mathrm{NF}-\kappa \mathrm{B}$ subunit p65 phosphorylation. Increased expression of p21WAF, a cell cycle regulator, fostered by $H$. pylori infection, removes HDAC1 from the promoter and leads to hyperacetylation of H4. In addition, $H$. pylori encoded effectors alter host epigenetic circuitry indirectly by releasing inflammatory cytokines (Xia et al. 2008; Fehri et al. 2009). H. pylori infection also promotes aberrant $5 \mathrm{mC}$ patterns at $\mathrm{CpG}$ islands of miRNA genes, the E-cadherin gene CDH1, DNA repair genes such as MLH1 and tumour suppressor genes such as USF1/2 and WWOX (Chan et al. 2003; Ando et al. 2009; Bussière et al. 2010; Yan et al. 2011).

\subsubsection{Legionella pneumophila: Legionella pneu-} mophila causes Legionnaire's disease by infecting alveolar macrophages. In lung epithelial cells, flagellin, a component of the flagellum, activates NF- $\kappa \mathrm{B} / \mathrm{RelA}$ and p38 MAPK signalling pathway causing acetylation of $\mathrm{H} 3$ and $\mathrm{H} 4$ and phosphorylation of $\mathrm{H} 3$ (Schmeck et al. 2008). L. pneumophila secretes four T4SS effectors: a SET domain and Ank repeat harboring histone methyltransferase LpSET, AnkX, SnpL, and AnkH. LpSET, a secreted protein, has been shown to modulate rRNA expression in the nucleolus by binding at the promoter and intergenic-spacer regions of the silent rDNA genes through its interaction with chromatin modulator HP1 and dimethylation of histone $\mathrm{H} 3$ on lysine 4. LpSet also known as RomA, can catalyses trimethylation of histone $\mathrm{H} 3$ on lysine 14 at the promoters of genes involved in innate immunity ( $\mathrm{Li}$ et al. 2013; Rolando et al. 2013).
SnpL interferes with mRNA processing and transcription elongation and inhibits SUPT5H, a DRB sensitivity-inducing factor (DSIF) complex component. AnkH targets LARP7, a small nuclear ribonucleoprotein (snRNP) complex component. Both AnkH and SnpL interferes with RNA pol II transcription elongation activity, and together both lead to genome-wide transcriptional reprogramming (Schuelein et al. 2018; Von Dwingelo et al. 2019).

5.1.14 Listeria monocytogenes: Four Listeria virulence factors, Listeriolysin (LLO), Internalin B (InlB), Listeria nuclear-targeted protein $\mathrm{A}(\mathrm{LntA})$ and OrfX interfere in cellular epigenetic mechanisms. LLO is a pore-forming, cholesterol-dependent cytolysin, which can trigger $\mathrm{K}+$ efflux and is involved in dephosphorylation of $\mathrm{H} 3 \mathrm{~S} 10$ and deacetylation of $\mathrm{H} 4$ at the promoters of proinflammatory chemokine CXCL2, phosphatase DUSP4 and the interferon regulatory factor IRF3 (Hamon et al. 2007; Hamon and Cossart 2011). LLO can also degrade Mre11, a double-strand DNA break sensor leading to increased phosphorylation of the histone variant H2AX (Hamon et al. 2007; Hamon and Cossart 2011).

Internalin B mimics hepatocyte growth factor (HGF), the physiological ligand of c-Met tyrosine kinase receptor, and impacts the chromatin regulation post priming by LLO. Interaction of InlB with cMet activates $\mathrm{PI} 3 \mathrm{~K}$ - Akt pathway translocating cytoplasmic SIRT2 to the nucleus. The nuclear SIRT2 deacetylates H3K18ac at TSS, which in turn leads to the silencing of genes encoding transcription factors (SMAD1, FOXM, IRF2), chromatin remodelling members (SMARCA2, SAP130) and cell signalling components (MAPK14, PIK3R3, PTPNG, SOS1, VAV3, ABL1, CAMK26, MAP2K6, LEF1, RASGRP1) (Eskandarian et al. 2013).

LntA accumulates in the host cell nucleus and targets BAHD1. BAHD1, a C-terminal BAH domain-containing protein, is involved in heterochromatinization through DNA methylation, histone modifications, and chromatin remodelling. BAHD1 responds to signalling cues in a cell-type-specific manner and causes gene repression. LntA is also known to subdue HDAC1/2 and BAHD1 recruitment to promoters of InterferonStimulated genes (ISG) that leads to deacetylation and upregulation of ISGs (Lebreton et al. 2011). OrfX binds and reduces cellular RYBP, a transcriptional zinc finger protein, inhibiting E3 ubiquitin ligase MDM2mediated degradation of $\mathrm{p} 53$. Thus, it indirectly provides survival advantage to the bacteria by regulating 
superoxide and nitric oxide production (Prokop et al. 2017).

\subsubsection{Mycobacterium tuberculosis: Mycobacterium} tuberculosis $(\mathrm{Mtb})$ is an intracellular bacterium and the causative bacteria of Tuberculosis. One of the most successful pathogenic bacteria known, $M t b$ creates for itself a niche inside the host macrophage by inhibiting the phagosome-lysosome fusion. The modulation of the host cellular machinery by $M t b$ is achieved either directly by secreting bacterial effector molecules that can modulate the host epigenome or indirectly by inducing host signalling pathways. Several studies, including ones from our own laboratory, have shown epigenetic modulation of the host epigenome by mycobacterial proteins. The modulation of the host epigenome takes place either through changes in the DNA methylation, post-translational modification of the histones or via regulatory non-coding RNAs. Differential methylation of the host genome upon $M t b$ infection has been reported. In addition to $\mathrm{CpG}$ dinucelotides, the differential methylation was noticed at non-CpG dinucleotide (Sharma et al. 2016). Rv2966c, a $M t b$-encoded methyltransferase, secreted into the host cells was found to be responsible for this non-canonical DNA methylation (Sharma et al. 2015). Both hypermethylation and hypomethylation of DNA were observed at several essential host defence genes. Proteins from Mycobacterium tuberculosis are also known to modify the host histones. Rv1988, was found to methylate histone $\mathrm{H} 3$ at $\mathrm{R} 42$ and suppress genes involved in the first line of host defence (Yaseen et al. 2015). Rv3423.1 was found to be a histone acetyltransferase that modulates the expression of anti-inflammatory host genes (Jose et al. 2016). Another mycobacterial protein, Enhanced Intracellular Survival protein (EIS alias Rv2416c) was shown to acetylate H3 at the IL-10 promoter helping M.tb to escape autophagy (Pacis et al. 2019).

\subsubsection{Mycobacterium leprae: Mycobacterium leprae} (ML), the bacilli that causes human leprosy, establishes infection in adult Schwann cells, primary nonimmune target cells causing neurological injury that leads to sensory motor loss. Schwann cells in adults infected with ML undergo a reprogramming that converts Schwann cells into progenitor/stem-like cells (pSLC) and promote bacterial dissemination. In pSLC, mesodermal/EMT genes, Twist1, Prrx $1, \operatorname{Tbx} \mathbf{1 8}$, and Bmp6, were found to be significantly hypomethylated, leading to a transcriptional activation of these genes. On the other hand, Sox $\mathbf{1 0}$ was significantly hypermethylated leading to the loss of Sox10 expression. These findings suggest that this reprogramming caused significant epigenetic changes in essential regulatory genes (Masaki et al. 2013). In addition, hsa-mir-21 RNA has been found to be upregulated upon ML infection leading to inhibited expression of the genes encoding the two vitamin Ddependent antimicrobial peptides, CAMP and DEFB4A (Liu et al. 2012).

\subsubsection{Porphyromonas gingivalis: Porphyromonas} gingivalis is responsible for periodontitis. This infection significantly decreases global $\mathrm{H} 3 \mathrm{~K} 4 \mathrm{me} 3$ in gingival epithelial cells (GECs). $P$. gingivalis lipopolysaccharide (Pg LPS) has been shown to significantly reduce the level of DNA methyltransferase, DNMT1 and HDAC1 and upregulate nuclear histone acetyltransferase $\mathrm{p} 300$. This was found to be correlated with changed expression of Alzheimer's disease-linked genes $A P P, A P P B P \mathbf{2}, I F N G R \mathbf{1}, M M P \mathbf{1}, M M P \mathbf{2}$ and $M M P 16$. Loss of $\mathrm{KDM} 3 \mathrm{C}$ in both human and mouse macrophages, in response to Pg LPS stimulation, induced pro-inflammatory cytokines, p65 phosphorylation, and accelerated its nuclear translocation. (Imai et al. 2009; Yin and Chung 2011).

In vitro infection with $P$. gingivalis led to an increase in expression of $\mathrm{B7}-\mathrm{H4}$ and lysine demethylase $5 \mathrm{~B}$ (KDM5B) (Diomede et al. 2017). Co-expression of B7$\mathrm{H} 4$ and KDM5B correlated significantly with a bacterial load and lead to acetylation of epithelial innate immune response genes $h B D \mathbf{2}$ and CCL20 (Olsen et al. 2017). In addition, miRNA-203 was also found to be upregulated along with upregulation of SOCS3 (Suppression of cytokine signalling 3) and SOCS6 genes (Lee et al. 2019).

5.1.18 Salmonella: Salmonella enterica acetyltransferase, AAC (60)-ly, belongs to the acetyltransferase superfamily that includes HATs, suggesting that it might be the bacterial ancestor of the eukaryotic HATs. In vitro studies have shown that AAC (60)-ly can acetylate histone proteins (Hamon and Cossart 2008).

The nuclear RNA decay factors, MTR4 and RRP6, are involved in the degradation of unstable nuclear ncRNAs, and their loss causes accumulation of unstable nuclear ncRNAs. Salmonella infection triggers the loss of nuclear RNA decay factors, resulting in the accumulation of unstable nuclear ncRNAs, resulting in the upregulation of immune genes (Imamura et al. 2018). On the other hand, Several members of the miR15 family inhibit Salmonella infection (Maudet et al. 2014). In addition, progressive loss of DNA 
methylation at multiple $\mathrm{CpG}$ sites has been observed in Salmonella-infected macrophages (Pacis et al. 2019).

\subsubsection{Shigella flexneri: Shigella flexneri targets} colonic epithelial cells causing bacillary dysentery. $S$. flexneri secretes four nucleomodulins, IpaB, IpaH9.8, OspB and OspF. OspF, a type III secreted effector protein, is a phosphothreonine lyase. It mediates conversion of a phosphothreonine residue into dehydrobutyrine, leading to irreversible inactivation of MAPK by preventing its phosphorylation (P38 and ERK). This abrogates subsequent histone H3S10 phosphorylation at a subset of NF-kB-regulated promoters and blocks inflammatory gene transcription. OspF also directly interacts with HP1 and dephosphorylates it at S83, by inactivating the kinase MSK1. The activity of OspF is unique, and no eukaryotic homolog has been identified (Arbibe et al. 2007).

Shigella infection induces an MTOR-dependent upregulation of mir 155 and mir31 levels, which in turn targets and regulates PP2A in the macrophages (Holla et al. 2014). Host miRNA miR-29b-2-5p has been found to have a dual role during Shigella infection. Host cells internalize Shigella, where it replicates and decreases levels of $m i R-29 b-2-5 p$, which contributes to a balanced intracellular replication, premature cell death evasion, and the efficient dissemination of Shigella to neighbouring cells (Grassl and Finlay 2007).

\subsubsection{Streptococcus pneumoniae: Streptococcus} pneumoniae is responsible for bacterial pneumonia and meningitis in the upper respiratory tract. Its poreforming toxin pneumolysin (PLY), along with the pyruvate oxidase $\mathrm{SpxB}$ is responsible for $\mathrm{H}_{2} \mathrm{O}_{2}$ production. The combined effects of PLY and $\mathrm{H}_{2} \mathrm{O}_{2}$ triggers host signalling that dephosphorylates H3S10, mediated by the host cell phosphatase PP1 (Dong et al. 2020). In addition, Streptococcus pneumoniae infection upregulates hsa-miR-200b that might promote pneumonia via targeting of KALRN (Huang et al. 2017).

5.1.21 Pseudomonas aeruginosa: P. aeruginosa, an opportunistic pathogen that typically infects and colonizes inflamed airways (e.g., in cystic fibrosis) and burn wounds, causes pneumonia, urinary tract infections, wound infections, acute otitis, and septicemia. The quorum-sensing signal 2-aminoacetophenone, released by $P$. aeruginosa, induces expression of HDAC1 in human THP-1 monocytes leading to global hypoacetylation of histone H3K18. Changes in acetylation marks dampen the induction of inflammatory cytokines and chemokines, including TNF, IL-1ß, and
MCP-1, impairing host cell responses to infection (Bandyopadhaya et al. 2016).

The secretory Pseudomonas proteins, PopB and PopD enter the host membrane to form a pore to accompany T3SS effectors that leads to potassium $(\mathrm{K}+)$ efflux as well as histone $\mathrm{H} 3$ modification. PopBPopD-dependent H3S10 dephosphorylation requires PP1 phosphatase, which affects infection (Dortet et al. 2018). In addition, microRNA 93 (miR-93), which is highly expressed in basal conditions, decreases during Pseudomonas infection along with increased expression of the IL-8 that in turn causes accumulation of neutrophils in the airways, leading to lung injury (Dortet et al. 2018).

5.1.22 Neisseria gonorrhoeae: $N$. gonorrhoeae causes the sexually transmitted disease gonorrhoea. It can survive in the host both extracellularly and intracellularly. The pathogen harbours the Gc-HDAC gene, a histone deacetylase-like enzyme that shares 3D-homology to human HDAC1, HDAC2, and HDAC8. $N$. gonorrhoeae infection causes reduction in the expression of host defence peptides LL-37, HBD-1, and SLPI in macrophages. It can modify host chromatin with enrichment of the epigenetic mark H3K9ac at the promoters of proinflammatory genes. Initial exposure to Neisseria or purified lipooligosaccharides (LOS) from Neisseria upregulates microRNA-146a, which in turn suppresses immune responses, and facilitates bacterial survival and dissemination (Zughaier et al. 2020).

In addition, epigenetic modulation of the host cell machinery has also been documented for other bacterial species including Actinobacteria, Aeromonas, Bordetella, Moraxella, Fusobacterium and Clostridium. Gram-positive Actinobacteria reside on human skin and mucosal surfaces and can be both commensal and opportunistic pathogens to humans. They produce metabolites that can interact with and modulate the host epigenetic machinery. Extracts of Actinobacteria $\mathrm{No}$ cardiopsis spp cause $60 \%$ inhibition of HDAC (comparable to $68 \%$ inhibition by the known HDAC inhibitor, trichostatin A) (Varghese et al. 2015). Aeromonas hydrophila, associated with gastroenteritis produces aerolysin, a pore-forming toxin. Aerolysin is known to induce $\mathrm{K}+$ efflux and decreases cellular H3S10phosphorylation ( Hamon and Cossart 2011). Bordetella bronchiseptica encodes a histone methyltransferase, BbSET, ectopic expression of which in HeLa cells causes dysregulation of ribosomal RNA transcription (Li et al. 2013). Moraxella catarrhalis induces $\mathrm{H} 3 \mathrm{~S} 10 \mathrm{ph} / \mathrm{H} 3 \mathrm{~K} 14 \mathrm{ac}$ through inflammatory 
signalling cascades and downregulates HDAC1/2 expression in bronchial epithelial cells (Slevogt et al. 2006). Downregulation of DNMT1, HDAC1and HDAC2 has been observed in the periodontal disease caused by Fusobacterium nucleatum (Yin and Chung 2011). A neurotoxin (BoNT) secreted by Clostridium botulinum has been shown to stimulate histone deacetylase HDAC4 and cause differential miRNA expression of miR-1/206 and miR-133 family of miRNAs. (Worton et al. 2018).

\subsection{Viral interaction with host epigenetic machinery}

DNA and RNA viruses promote their infectivity and latency when their early proteins interact with cellular regulatory elements of the host, which then serves as the checkpoint for specific or global gene regulation. To modulate their environment for successful infection, different viruses employ strategies of targeting the cellular pool of host factors. Prime candidates for such epigenetic control includes host gene involved in: cell cycle progression, senescence, survival, inflammation, and immunity. Discussed below are some examples of host-viral interaction at the epigenetic front.

5.2.1 Human adenovirus (HAdv): Adenoviruses are associated with diseases including gastroenteritis, conjunctivitis, hepatitis, myocarditis, and pneumonia. Human Adenovirus (HAdv) is responsible for $5-7 \%$ of global upper respiratory tract paediatric cases, including the common cold. Nuclear replicating viruses have evolved to manipulate the host machinery to promote infection and evade the cellular defence system. Adenoviral infection is correlated with increased acetylation of $\mathrm{H} 3$ at the active viral gene promoters. The acetylation leads to increased expression of the active viral genes. Daxx/ATRX histone chaperone complex is required to maintain the $\mathrm{H} 3 \mathrm{~K} 9 \mathrm{me} 3$ silencing mark at specific heterochromatin loci (Zughaier et al. 2020). Along with Sp100, the complex restricts viral chromatinization at the early stages of infection. Adenovirus induces E1B-55K mediated proteasomal degradation of Daxx/ATRX, thereby removing the barricade of viral chromatinization and early-stage infection (Horwitz et al. 2008; Schreiner et al. 2010).

5.2.2 Kaposi's sarcoma-associated virus (KSHV): Kaposi's sarcoma-associated virus is associated with sarcoma and lymphoproliferative diseases and is known to stay latent for lifetime in the host. The combination of histone modifications serves as a switch for the virus to transform from latent to lytic cycle. The latent viral genome associates with a combination of both active [acetylated $\mathrm{H} 3$ (H3ac) and $\mathrm{H} 3 \mathrm{~K} 4 \mathrm{me} 3$ ] and repressive [H3K9me3 and $\mathrm{H} 3 \mathrm{~K} 27 \mathrm{me} 3$ ] histone modification marks. Upon reactivation, the viral genome shows a gain of $\mathrm{H} 3$ acetylation, $\mathrm{H} 3 \mathrm{~K} 4$ methylation and loss of $\mathrm{H} 3 \mathrm{~K} 27 \mathrm{me} 3$ at genomic region encoding for IE genes ORF50 and ORF48 (Toth et al. 2010). Reactivation of the lytic cycle dissipates the H3K27me3 mark ubiquitously deposited on the entire KSHV genome by methyltransferase EZH2. The reactivation also results in decreased H3K27me3 and increased IE/E lytic gene expression (Toth et al. 2010).

The KSHV genome does not show a gain of DNA methylation upon infection. However, the virus can manipulate host DNA by altering DNA methylation. KSHV encoded latency-associated nuclear antigen (LANA) interacts with DNMT3a, the de novo DNA methyltransferase, and has been shown to downregulate the expression of H-cadherin and TGF- $\beta$ type II receptor $(T \beta R I I)$ genes through this interaction. By decreasing T $\beta$ RII expression, KSHV targets both the host anti-proliferative effects as well as the immune response. Upon infection, KSHV encoded ORF50 mRNA acquires m6A methylation mediated stabilization. ORF50 (RTA) serves as a key KSHV lytic switch (Shamay et al. 2006; Baquero-Perez et al. 2019).

\subsubsection{Epstein-Barr virus (EBV): Epstein - Barr virus} has a biphasic viral life cycle of latency and lytic reactivation. EBV attacks the memory $\mathrm{B}$ cells and epithelial cells for persistent latent infection. EBV employs epigenetic reprogramming of self as well as the host cellular machinery to maintain its latency or switch to reactivation/lytic phase. The Trans activator protein BZFL1 functions as a switch from latency to lytic cycle (Bhende et al. 2004; Dickerson et al. 2009). EBV DNA acquires CpG methylation after the proliferation of infected cells. BZFL1 binds to the methylated promoter of lytic genes but does not bind to unmethylated DNA efficiently to activate the latent/lytic transition post establishment of latent infection. The EBV chromatin acquires changes in histone modifications between the latent and lytic cycle. During latency, the associated genes such as $\mathrm{Cp}$ and the LMP1/LMP2 promoters are associated with active chromatin marks including $\mathrm{H} 3 \mathrm{~K} 9 \mathrm{ac}, \mathrm{H} 3 \mathrm{~K} 27 \mathrm{ac}$, and $\mathrm{H} 3 \mathrm{~K} 4 \mathrm{ac}$ while transcriptionally silenced gene promoters such as BZLF1 and BRLF1 remain enriched for inactive chromatin marks including $\mathrm{H} 3 \mathrm{~K} 9 \mathrm{me} 3$ and H3K27me3. Once activated, BZLF1 and BRLF1 
interact with the methylated promoters of lytic genes leading to efficient viral replication and progeny production (Ichikawa et al. 2018).

EBV also epigenetically manipulates the proliferative and anti-apoptotic properties of infected cells for persistent latency. EBV infection leads to depletion of the $\mathrm{H} 3 / \mathrm{H} 4$ acetylation marks at the Bim promoter, followed by an increase in $\mathrm{CpG}$ methylation. Normally, the promoter of p16 (INK4A) maintains the combination of the repressive $\mathrm{H} 3 \mathrm{~K} 27 \mathrm{me} 3$ and activating H3K4me3 modification. The EBV nuclear protein EBNA3A increases the H3K27me3 mark at p16 (INK4A) promoter leading to transcriptional silencing of the gene. The reprogramming of Bim and p16 (INK4A) by EBV inhibits cell death and senescence, paving the path for the persistence of latent infection and transformation of host cells. Furthermore, EBV infection down-regulates DNA repair pathway genes by modifying the histone bivalent marks H3K27me3 and $\mathrm{H} 3 \mathrm{~K} 4 \mathrm{me} 3$ in nasopharyngeal epithelial cells (Leong et al. 2019).

5.2.4 Human immunodeficiency virus (HIV): HIV infection causes acquired immunodeficiency syndrome (AIDS). HIV remains transcriptionally silent inside the cells by employing epigenetic reprogramming of the viral and host genes. The interplay of HIV and host has been shown to have an impact on histone modifications, DNA methylation as well as RNA methylation. DNA methylation: The HIV infection is concomitant with changes in host genome $\mathrm{CpG}$ methylation and methyltransferase expression levels. FOXP3, interleukin 2 (IL-2), IGFBP6, and SATB2 and CCR5, genes associated with immune response and $\mathrm{T}$ cell expression/ activation, gain $\mathrm{CpG}$ methylation upon infection (Pion et al. 2013; Nakayama-Hosoya et al. 2015; Gornalusse et al. 2015). The methyl-CpG binding domain protein 2 (MBD2) along with HDAC2 binds to the CpG flanking the TSS of HIV-1, contributing to HIV-1 latency in infected Jurkat cells and primary CD4+ cells (Kauder et al. 2009).

RNA methylation and ncRNA: Methylation also significantly regulates HIV-1 RNA metabolism and replication. The m5C RNA methyltransferase (MTase) DNMT2 mediated methylation of the HIV genome promotes viral infection by providing post-transcriptional stability to HIV-RNA (Dev et al. 2017). However, the m5C RNA methyltransferase NOP2/NSUN1 restricts HIV provirus transcription and promotes latency (Kong et al. 2020). Moreover, HIV infection in $\mathrm{CD} 4+$ cells has been correlated with increase in m6A methylation in both HIV RNA and host mRNAs
(Lichinchi et al. 2016a). HIV RNA genome also acquires host 2'-O-MTase FTSJ3 dependent internal 2'O-methylation that aids the virus in escaping MDA5 mediated immune surveillance (Li 2019). In addition, HIV encoded antisense ncRNA, ASP, recruits PRC2 complex at HIV promoters, and drives deposition of H3K27me3 resulting in nucleosome assembly and suppressing gene expression. On the other hand, the host ncRNAs MALAT1, uc002yug.2 and HEAL (HIV1-enhanced lncRNA) regulates HIV transcription (Zapata et al. 2017; Huan et al. 2018; Qu et al. 2019)

Histone modifications: HIV latency has been correlated with $\mathrm{CBF}-1$, c-Myc and Sp1 dependent recruitment of HDAC1 complex to LTR of latent proviruses that inhibits recruitment of RNAPII (Jiang et al. 2007). Proviral latency is also linked with HKMTs, EZH2 Suv39h1, and CTIP-2 dependent H3K9me3 and $\mathrm{H} 3 \mathrm{~K} 27$ me3 modification of HIV-1 promoter (Friedman et al. 2011). During early and chronic infection, the polycomb repressive complex 2 (PRC-2) mediates H3K27 trimethylation of HIV-1 LTR leading to transcription repression heterogeneity (Matsuda et al. 2015).

5.2.5 Coronaviruses (CoV): Coronaviruses have pathologies in humans as well as in animals with bats as their natural hosts. CoVs are associated with upper respiratory tract pandemics: severe acute respiratory syndrome (SARS), Middle East respiratory syndrome (MERS) and SARS-COV2. SARS-CoV infection causes increase in $\mathrm{H} 3 \mathrm{~K} 4 \mathrm{me} 3$ and $\mathrm{H} 3 \mathrm{~K} 27 \mathrm{me} 3$ mark at the promoter of the interferon-stimulated genes (ISGs), leading to active transcription of ISG. MERS$\mathrm{CoV}$ infection leads to increased $\mathrm{H} 3 \mathrm{~K} 27 \mathrm{me} 3$ and decreased $\mathrm{H} 3 \mathrm{~K} 4 \mathrm{me} 3$ at ISG promotor (Schäfer and Baric 2017) and gain of DNA methylation at the promoters of CIITA, HLA-E, and PSMB9 decreasing interferon-stimulated genes and antigen presentation (Menachery et al. 2018). The SARS-CoV-2 evades zinc-finger antiviral protein (ZAP), a host antiviral defence, by evolving extreme $\mathrm{CpG}$ deficiency (Xia 2020).

Coronaviruses are known to acquire RNA cap methylation to surpass the host antiviral immune response by camouflaging its non-self mRNA as host self mRNA. MERS-CoV encoded SAM dependent 2'O-methyltransferase (2'-O-MTase) and the non-structural protein 16 (nsp16)/nsp10 complex converts $7 \mathrm{mGpppG}$ (cap-0) into 7mGpppG2'Om (cap-1) RNA to escape cellular immune response. SARS CoV-2 has at least 41 RNA modification sites on CoV-2 transcripts, with AAGAA being the most abundant motif. 
The role in pathogenicity and mechanism of CoV epitranscriptome remains to be elucidated (Kim et al. 2020; Viswanathan et al. 2020).

5.2.6 Influenza virus: The influenza virus is categorized into type A, B, and C. Group A virus is associated with severe pandemics such as H1N1 swine-origin flu. The influenza virus translates into cytokine surge in infected host cells. It alters the promoter DNA methylation profile of pro-inflammatory cytokines CXCL14, CCL25, CXCL6, and interleukins IL13, IL17C, IL4R. Cells infected with the HPAI-H5N1 virus show hypomethylation of IL17C and IL13 genes, increasing expression of these interleukins (Mukherjee et al. 2013).

Influenza virus-encoded nonstructural protein 1 (NS1) interacts with DNMT3B and relocates it to cytoplasm wherein K48-linked ubiquitination results in DNMT3B degradation. The NS1 mediated depletion of DNMT3B hypomethylates key suppressor genes of the JAK-STAT signalling pathway compromising cellular immunity (Liu et al. 2019). The Influenza virus-encoded nucleoprotein (NP) functions as a histone homolog. Host acetyltransferases GCN5 and PCAF differentially acetylate NP and regulate viral polymerase activity. CAF and GCN5 target Lys-31 and Lys90 of NP. Acetylation of Lys-90 of NP favours viral polymerase activity, however Lys-31 acetylation suppresses it, suggesting differential regulation of viral replication. H5N1 infections deplete the H3K4me3 activation mark on MHC locus and downregulate antigen presentation gene expression (Hatakeyama et al. 2018).

Along with these group of viruses, changes in the epigenetic circuitry by viral encoded factors has also been reported for Zika, Ebola and SV40. Zika virus infection of human neural progenitor cells (hNPC) is associated with host methyltransferase METTL3, METTL14, and demethylases ALKBH5 and FTO dependent m6A methylation of viral RNA. (Lichinchi et al. 2016b). Ebola virus encodes a large protein (L protein), which functions as a substrate-specific methyltransferase. It also possesses an internal adenosine-specific 2'O methyltransferase activity. The 2'O methylation seems to protect the viral RNA from the host immune system. (Martin et al. 2018). The simian virus 40, an oncogenic DNA virus, belonging to the Papovaviridae family, has been shown to acquire chromatin organisation with specific histone modifications during infection. SV40 infection is also correlated with increase in steady-state levels of histone acetyltransferase (HAT) p300/CBP (Sáenz Robles et al. 2013).

\subsection{Fungal epigenetic modulation during host- pathogen interaction}

Fungal infections have a remarkable impact on human health and survival-with an estimate of 15 million deaths and over 1 billion people being infected - and is a life-threatening disease in immunocompromised patients. Four genera of fungal species contribute to fungal infections: Aspergillus, Candida, Cryptococcus, and Pneumocystis. Epigenetic modulation of gene silencing and switching is one of the evasion mechanisms of the host immune system, but we inadequately understand it in human fungal pathogens.

5.3.1 Candida albicans: C. albicans localizes to various parts of the human body: skin, genitals, gastrointestinal tracts, and internal organs. Immunity of host, environmental factors, and interactions with other components of resident microbiota influence its pathogenicity. C. albicans survive in the human body by extensively adapting to nutrient availability, host immune system, and interacting with the human microbiome such as $S$. epidermidis and $P$. acnes.

DNA methylation in C. albicans is restricted to structural genes that modulate transcriptional activities, whereas repeat sequences and multigene families are comparatively free of DNA methylation; for instance, studies report methylation of INP51, MUC1, and LIP8 genes, which are related to pathogenicity and virulence (Mishra et al. 2011). The cell wall protein $\beta$-glucans induce functional reprogramming of monocytes by elevating $\mathrm{H} 3 \mathrm{~K} 4 \mathrm{me} 3$ levels at the promoters of TNF- $\alpha$, IL -6, and IL- 18 through dectin - 1/ Raf - 1 pathway. C. albicans protein Rtt109 acetylates H3K56 and exhibits a significant role in virulence in the mouse model (Da Rosa et al. 2010). SUMOylation modulates virulence by targeting CaSlp3 (Stomatin like protein 3) that relocates to the plasma membrane and vacuole (Sahu et al. 2020).

Apart from the Candida species, in Aspergillus fumigatus, an opportunistic Saccharomycota fungus, the role of $\mathrm{H} 3 \mathrm{~K} 9$ methyltransferase $\mathrm{ClrD} / \mathrm{su}($ var)3-9 and histone deacetylase Hdal has been shown (Palmer et al. 2008). Another opportunistic pathogen, Cryptococcus neoformans, has SAGA (Spt3-Ada2-Gen5) complex that is involved in the remodeling of chromatin through acetylation of histones, and its 


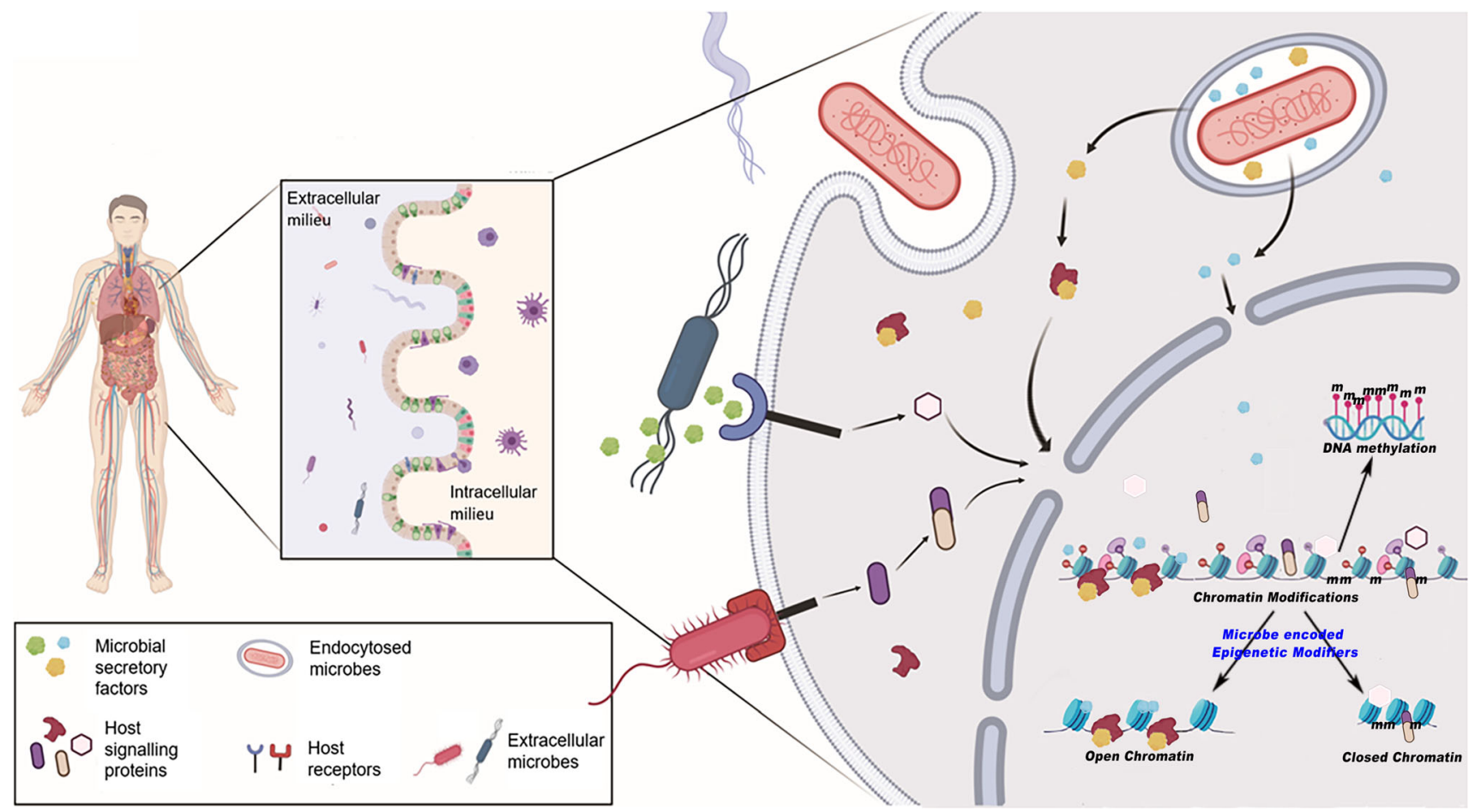

Figure 4. Epigenetic interaction of microbes with host cell. A cartoon depicting multiple ways by which microbe-host cell interaction can influences host epigenetic circuitry. (i) Modulation of chromatin organisation through interaction of the microbe (extracellular) with the host receptor that activates signalling cascade(s). (ii) Release of factors by extracellular or intracellular microbe in the host cells can that can interact with host factors having capability of modulating chromatin conformation. (iii) Secretion of microbial factors in the extracellular or intracellular milieu which upon entry into host cell nucleus interact directly with the chromatin directly. All these pathways individually or in concert can change both histone modifications and DNA methylation leading to changes in the chromatin conformation.

components Gcn5 and Ada2 are essential for virulence. (O’Meara et al. 2010).

\section{Conclusion}

Functional integrity of cells in a multicellular organism is maintained by their epigenetic circuitry. Epigenetic modifications not only modulate gene expression in a cell during development and differentiation but also in response to environmental challenges. The microbes that surround us or reside within our body can have a symbiotic relationship or can cause disease. As discussed in this review, data now exist for several microbial species, including bacteria, viruses and fungi, which demonstrates the interaction of microbial factors with the host chromatin and the epigenetic circuitry. The extracellular microbial interaction with the host epigenetic circuitry can be achieved by (i) binding to the host receptor which can activate downstream signalling cascade leading to modulation of chromatin organisation; or (ii) microbial factors secreted in extracellular milieu which enter host cells and interact with the chromatin directly or indirectly by binding to host factors, which in turn can translocate to the nucleus. Intracellular microbe after entering the host cells can release factors that can (i) interact with host factors having capability of modulating chromatin conformation or (ii) directly interact with chromatin. This interaction of the host and the microbe can have a profound effect on epigenetic modifications and chromatin conformation of multiple genes in the host cell, leading to abnormal cellular functions (figure 4). Multiple microbiome studies (Eloe-Fadrosh and Rasko 2013; Cortese et al. 2016) have brought out the correlation between changes in microbial consortia and human diseases. We, based on the literature discussed above, strongly believe dysregulation of epigenetic circuitry by microorganisms to be the basis of several of these human diseases.

An organism during its interaction with the environment acquires characters, some of which are 
transmitted to subsequent generations. Over the past few years, several studies have indicated this transmission to be non-genetic, by the inheritance of epigenetic marks across multiple generations (Thamban v. 2020). Therefore, it is possible that the epigenetic changes (sometimes also referred to as epimutations (Zoghbi et al. 2016)), brought out in a cell due to its interaction with a microorganism, are inherited. Whether an epimutation, which is acquired by somatic cells due to its interaction with a microorganism, could passed on to the next generation remains an enigma. However, if this hypothesis is proven to be true, epigenetic interface in the interaction between microbes and human cells could provide a mechanism by which rapid and dynamic co-evolution of the interacting species could be achieved.

\section{Acknowledgements}

APD, RR, VA and AS are recipients of Senior Research Fellowship of the Department of Biotechnology (DBT), Council of Scientific and Industrial Research (CSIR) and University Grants Commission (UGC), India respectively towards the pursuit of a $\mathrm{PhD}$ degree of the Manipal University, Manipal, and Regional Centre for Biotechnology. Research in SK laboratory is supported by grants from DBT, SERB, DST, CDFD and CSIR-IMTECH.

\section{References}

Ando T, Yoshida T, Enomoto S, Asada K, Tatematsu M, Ichinose M, Sugiyama T and Ushijima T 2009 DNA methylation of microRNA genes in gastric mucosae of gastric cancer patients: Its possible involvement in the formation of epigenetic field defect. Int. J. Cancer 124 2367-2374

Arand J, Spieler D, Karius T, Branco MR, Meilinger D, Meissner A, Jenuwein T, Xu G, et al. 2012 In vivo control of $\mathrm{CpG}$ and non-CpG DNA methylation by DNA methyltransferases. PLoS Genet. 8 e 1002750

Arber W and Linn S 1969 DNA modification and restriction. Annu. Rev. Biochem. 38 467-500

Arbibe L, Kim DW, Batsche E, Pedron T, Mateescu B, Muchardt C, Parsot C and Sansonetti PJ 2007 An injected bacterial effector targets chromatin access for transcription factor NF- j B to alter transcription of host genes involved in immune responses. Nat. Immunol 8 47-56

Balacco DL and Soller M 2019 The m6A writer: rise of a machine for growing tasks. Biochemistry 58 363-378
Bandyopadhaya A, Tsurumi A, Maura D, Jeffrey KL and Rahme LG 2016 A quorum-sensing signal promotes host tolerance reprogramming. Nat. Microbiol. 1 1-9

Bannister AJ and Kouzarides T 2011 Regulation of chromatin by histone modifications. Cell Res. 21 381-395

Baquero-Perez B, Antanaviciute A, Yonchev ID, Carr IM, Wilson SA and Whitehouse A 2019 The Tudor SND1 protein is an m6A RNA reader essential for replication of Kaposi's sarcoma-associated herpesvirus. Elife 8 e47261

Bardwell AJ, Abdollahi M and Bardwell L 2004 Anthrax lethal factor-cleavage products of MAPK (mitogen-activated protein kinase) kinases exhibit reduced binding to their cognate MAPKs. Biochem. J. 387 569-577

Barnes CE, English DM and Cowley SM 2019 Acetylation and Co: An expanding repertoire of histone acylations regulates chromatin and transcription. Essays Biochem. 63 97-107

Bass BL 2002 RNA editing by adenosine deaminases that act on RNA. Annu. Rev. Biochem. 71 817-846

Becker PB and Workman JL 2013 Nucleosome remodeling and epigenetics. Cold Spring Harb. Perspect. Biol. 5 a017905

Bhat MI and Kapila R 2017 Dietary metabolites derived from gut microbiota: Critical modulators of epigenetic changes in mammals. Nutr. Rev. 75 374-389

Bhat MI, Kumari A, Kapila S and Kapila R 2019 Probiotic lactobacilli mediated changes in global epigenetic signatures of human intestinal epithelial cells during Escherichia coli challenge. Ann. Microbiol. 69 603-612

Bhende PM, Seaman WT, Delecluse H-J and Kenney SC 2004 The EBV lytic switch protein, Z, preferentially binds to and activates the methylated viral genome. Nat. Genet. 36 1099-1104

Bierne H, Tham TN, Batsche E, Dumay A, Leguillou M, Golsteyn SK, Regnault B, Seeler JS, Muchardt C, Feunteun J and Cossart P 2009 Human BAHD1 promotes heterochromatic gene silencing. Proc. Natl. Acad. Sci. USA 106 13826-13831

Blanc RS and Richard S 2017 Arginine methylation: The coming of age. Mol. Cell 65 8-24

Blow MJ, Clark TA, Daum CG, Deutschbauer AM, Fomenkov A, Fries R, Froula J, Kang DD, et al. 2016 The epigenomic landscape of prokaryotes. PLoS Genet. 12 e 1005854

Bobetsis YA, Barros SP, Lin DM, Arce RM and Offenbacher S 2010 Altered gene expression in murine placentas in an infection-induced intrauterine growth restriction model: A microarray analysis. J. Reprod. Immunol. 85 140-148

Boccaletto P, MacHnicka M, Purta E, Pitkowski P, Baginski B, Wirecki T, De Crécy-Lagard V, Ross R, et al. 2018 MODOMICS: A database of RNA modification pathways. Nucleic Acids Res. 46 D303-307

Borjesson DL, Kobayashi SD, Whitney AR, Voyich JM, Argue CM and DeLeo FR 2005 Insights into pathogen immune evasion mechanisms: Anaplasma phagocytophilum fails to induce an Apoptosis differentiation 
program in human neutrophils. J. Immunol. 174 6364-6372

Bourc'his D, Xu GL, Lin CS, Bollman B and Bestor TH 2001 Dnmt3L and the establishment of maternal genomic imprints. Science 294 2536-2539

Brennan CA and Garrett WS 2019 Fusobacterium nucleatum-symbiont, opportunist and oncobacterium. Nat. Rev. Microbiol. 17 156-166

Bussière FI, Michel V, Mémet S, Avé P, Vivas JR, Huerre M and Touati E 2010 H. pylori-induced promoter hypermethylation downregulates USF1 and USF2 transcription factor gene expression. Cell. Microbiol. 12 1124-1133

Cao J and Yan Q 2012 Histone ubiquitination and deubiquitination in transcription, DNA damage response, and cancer. Front. Oncol. 226

Chan AOO, Lam SK, Wong BCY, Wong WM, Yuen MF, Yeung YH, Hui WM, Rashid A, et al. 2003 Promoter methylation of E-cadherin gene in gastric mucosa associated with Helicobacter pylori infection and in gastric cancer. Gut 52 502-506

Choung HK, Kim YA, Lee MJ, Kim N and Khwarg SI 2012 Multigene methylation analysis of ocular adnexal MALT lymphoma and their relationship to Chlamydophila psittaci infection and clinical characteristics in South Korea. Invest. Invest. Ophthalmol. vis. Sci. 53 1928-1935

Cizmeci D, Dempster EL, Champion OL, Wagley S, Akman OE, Prior JL, Soye OS, Mill J and Titball RW 2016 Mapping epigenetic changes to the host cell genome induced by Burkholderia pseudomallei reveals pathogen-specific and pathogen-generic signatures of infection. Sci. Rep. 630861

Corrêa RO, Vieira A, Sernaglia EM, Lancellotti M, Vieira AT, Avila-Campos MJ, Rodrigues HG and Vinolo MAR 2017 Bacterial short-chain fatty acid metabolites modulate the inflammatory response against infectious bacteria. Cell. Microbiol. 197

Cortese R, Lu L, Yu Y, Ruden D and Claud EC 2016 Epigenome-Microbiome crosstalk: A potential new paradigm influencing neonatal susceptibility to disease. Epigenetics 11 205-215

Czech B and Hannon GJ 2016 One loop to rule them all: The ping-pong cycle and piRNA-guided silencing. Trends Biochem. Sci. 41 324-337

Deaton AM and Bird A $2011 \mathrm{CpG}$ islands and the regulation of transcription. Genes Dev. 25 1010-1022

Derrien T, Johnson R, Bussotti G, Tanzer A, Djebali S, Tilgner H, Guernec G, Martin D, et al. 2012 The GENCODE v7 catalog of human long noncoding RNAs: Analysis of their gene structure, evolution, and expression. Genome Res. 22 1775-1789

Dev RR, Ganji R, Singh SP, Mahalingam S, Banerjee S and Khosla S 2017 Cytosine methylation by DNMT2 facilitates stability and survival of HIV-1 RNA in the host cell during infection. Biochem. J. 474 2009-2026

Dickerson SJ, Xing Y, Robinson AR, Seaman WT, Gruffat H and Kenney SC 2009 Methylation-dependent binding of the Epstein-Barr virus BZLF1 protein to viral promoters. (ed )SH Speck. PLoS Pathog. 5 e1000356

Ding SZ, Fischer W, Kaparakis-Liaskos M, George Liechti D, Merrell S, Grant PA, Ferrero RL, Crowe SE, Haas R, Hatakeyama M and Goldberg JB 2010 Helicobacter pylori-induced histone modification, associated gene expression in gastric epithelial cells, and its implication in pathogenesis. PLoS ONE 13710009875

Diomede F, Thangavelu SR, Merciaro I, D’Orazio M, Bramanti P, Mazzon E and Trubiani O 2017 Porphyromonas gingivalis lipopolysaccharide stimulation in human periodontal ligament stem cells: Role of epigenetic modifications to the inflammation. Eur. J. Histochem. 61 231-237

Dominissini D, Nachtergaele S, Moshitch-Moshkovitz S, Peer E, Kol N, Ben-Haim MS, Dai Q, Di Segni A, et al. 2016 The dynamic N1 -methyladenosine methylome in eukaryotic messenger RNA. Nature 485 201-206

Dominissini D, Moshitch-Moshkovitz S, Schwartz S, Salmon-Divon M, Ungar L, Osenberg S, Cesarkas K, JacobHirsch J, et al. 2012 Topology of the human and mouse m6A RNA methylomes revealed by m6A-seq. Nature 530 441-446

Dong W, Rasid O, Chevalier C, Connor M, Eldridge MJG and Hamon MA 2020 Streptococcus pneumoniae infection promotes Histone $\mathrm{H} 3$ dephosphorylation by modulating host PP1 phosphatase. Cell Rep. 30 4016-4026.e4

Dortet L, Lombardi C, Cretin F, Dessen A and Filloux A 2018 A. Pore-forming activity of the Pseudomonas aeruginosa type III secretion system translocon alters the host epigenome. Nat. Microbiol. 3 378-386

Duan L, Yi M, Chen J, Li S and Chen W 2016 Mycobacterium tuberculosis EIS gene inhibits macrophage autophagy through up-regulation of IL-10 by increasing the acetylation of histone H3. Biochem. Biophys. Res. Commun. 473 1229-1234

Dumler JS, Sinclair SH, Pappas-Brown V and Shetty AC 2016 Genome-wide anaplasma phagocytophilum ankadna interactions are enriched in intergenic regions and gene promoters and correlate with infection-induced differential gene expression. Front. Cell. Infect. Microbiol. 697

Dunphy PS, Luo T and McBride JW 2014 Ehrlichia chaffeensis exploits Host SUMOylation pathways to mediate effector-host interactions and promote intracellular survival. Infect. Immun. 82 4154-4168

Duriez P, Clermont O, Bonacorsi S, Bingen E, Chaventré A, Elion J, Picard B and Denamur E 2001 Commensal Escherichia coli isolates are phylogenetically distributed among geographically distinct human populations. $\mathrm{Mi}$ crobiology 147 1671-1676

Dwingelo JV, Chung IYW, Price CT, Li L, Jones S, Cygler $\mathrm{M}$ and Kwaik YA 2019 Interaction of the Ankyrin H core effector of legionella with the host LARP7 component of the 7SK snRNP complex. Mbio 10 e01942 
Eloe-Fadrosh EA and Rasko DA 2013 The human microbiome: From symbiosis to pathogenesis. Annu. Rev. Med. 64 145-163

Eskandarian HA, Impens F, Nahori MA, Soubigou G, Coppée JY, Cossart P and Hamon MA 2013 A role for SIRT2-dependent histone H3K18 deacetylation in bacterial infection. Science 3411238858

Farris TR, Dunphy PS, Zhu B, Kibler CE and McBride JW 2016 Ehrlichia chaffeensis TRP32 is a nucleomodulin that directly regulates expression of host genes governing differentiation and proliferation. Infect. Immun. $\mathbf{8 4}$ 3182-3194

Fehri LF, Rechner C, Janßen S, Mak TN, Holland C, Bartfeld S, Brüggemann H and Meyer TF 2009 Helicobacter pylori-induced modification of the histone $\mathrm{H} 3$ phosphorylation status in gastric epithelial cells reflects its impact on cell cycle regulation. Epigenetics 4 577-586

Fournier A, Sasai N, Nakao M and Defossez PA 2012 The role of methyl-binding proteins in chromatin organization and epigenome maintenance. Brief. Funct. Genomics 11 251-264

Friedman J, Cho W-K, Chu CK, Keedy KS, Archin NM, Margolis DM and Karn J 2011 Epigenetic silencing of HIV-1 by the histone H3 lysine 27 methyltransferase enhancer of Zeste 2. J. Virol. 85 9078-9089

Fu Y, Luo GZ, Chen K, Deng X, Yu M, Han D, Hao Z, Liu J, et al. 2015 N6-methyldeoxyadenosine marks active transcription start sites in Chlamydomonas. Cell 161 879-892

Füllgrabe J, Hajji N and Joseph B 2010 Cracking the death code: Apoptosis-related histone modifications. Cell Death Differ. 17 1238-1243

Garcia-Garcia JC, Rennoll-Bankert KE, Pelly S, Milstone AM and Dumler JS 2009 Silencing of host cell CYBB gene expression by the nuclear effector AnkA of the intracellular pathogen anaplasma phagocytophilum. Infect. Immun. 77 2385-2391

Ghadimi D, Helwig U, Schrezenmeir J, Heller KJ and de Vrese M 2012 Epigenetic imprinting by commensal probiotics inhibits the IL-23/IL-17 axis in an in vitro model of the intestinal mucosal immune system. $J$. Leukoc. Biol. 92 895-911

Giahi L, Aumueller E, Elmadfa I and Haslberger AG 2012 Regulation of TLR4, p38 MAPkinase, IKB and mirnas by inactivated strains of lactobacilli in human dendritic cells. Benef. Microbes 3 91-98

Goll MG, Kirpekar F, Maggert KA, Yoder JA, Hsieh CL, Zhang X, Golic KG, Jacobsen SE and Bestor TH 2006 Methylation of tRNAAsp by the DNA methyltransferase homolog Dnmt2. Science 311 395-398

Gornalusse GG, Mummidi S, Gaitan AA, Jimenez F, Ramsuran V, Picton A, Rogers K, Manoharan MS, et al. 2015 Epigenetic mechanisms, T-cell activation, and CCR5 genetics interact to regulate T-cell expression of CCR5, the major HIV-1 coreceptor. Proc. Natl. Acad. Sci. 112 E4762-4771

Grassl GA and Finlay BB 2007 Shigella rewrites host transcriptional responses. Nat Immunol. 8 15-16

Greenberg MVC and Bourc'his D 2019 The diverse roles of DNA methylation in mammalian development and disease. Nat. Rev. Mol. Cell Biol. 20 590-607

Greer EL, Blanco MA, Gu L, Sendinc E, Liu J, AristizábalCorrales D, Hsu CH, Aravind L, He C and Shi Y 2015 DNA methylation on N6-adenine in C. elegans. Cell 161 868-878

Greer EL and Shi Y 2012 Histone methylation: A dynamic mark in health, disease and inheritance. Nat. Rev. Genet. 13 343-357

Guo H, Zhu P, Yan L, Li R, Hu B, Lian Y, Yan J, Ren X, et al. 2014 The DNA methylation landscape of human early embryos. Nature 511 606-610

Ha SD, Reid C, Meshkibaf S and Kim SO 2016 Inhibition of interleukin $1 \beta$ (IL-1 $\beta$ ) expression by anthrax Lethal Toxin (LeTx) is reversed by histone deacetylase 8 (HDAC8) inhibition in murine macrophages. J. Biol. Chem. 511 606-610

Haller D, Holt L, Kim SC, Schwabe RF, Sartor RB and Jobin C 2003 Transforming growth factor- $\beta 1$ inhibits non-pathogenic Gram-negative bacteria-induced NF- $\mathrm{kB}$ recruitment to the interleukin- 6 gene promoter in intestinal epithelial cells through modulation of histone acetylation. J. Biol. Chem. 278 23851-23860

Hamon MA, Batsché E, Régnault B, To NT, Seveau S, Muchardt C and Cossart P 2007 Histone modifications induced by a family of bacterial toxins. Proc. Natl. Acad. Sci. u. s. a. 104 13467-13472

Hamon MA and Cossart P 2008 Histone modifications and chromatin remodeling during bacterial infections. Cell Host Microbe 4 100-109

Hamon MA and Cossart P $2011 \mathrm{~K}+$ efflux is required for histone $\mathrm{H} 3$ dephosphorylation by Listeria monocytogenes listeriolysin $\mathrm{O}$ and other pore-forming toxins. Infect. Immun. 79 2839-2846

Hatakeyama D, Shoji M, Yamayoshi S, Yoh R, Ohmi N, Takenaka S, Saitoh A, Arakaki Y, et al. 2018 Influenza A virus nucleoprotein is acetylated by histone acetyltransferases PCAF and GCN5. J. Biol. Chem. 293 7126-7138

Heyn H and Esteller M 2015 An adenine code for DNA: A second life for N6-methyladenine. Cell 161 710-713

Holla S, Kurowska-stolarska M, Bayry J and Balaji KN 2014 Selective inhibition of IFNG-induced autophagy by Mir155 - and Mir31 -responsive WNT5A and SHH signalling. Autophagy 10 37-41

Horwitz GA, Zhang K, McBrian MA, Grunstein M, Kurdistani SK and Berk AJ 2008 Adenovirus small ela alters global patterns of histone modification. Science $\mathbf{3 2 1}$ 1084-1085 
Hsu PJ, Zhu Y, Ma H, Guo Y, Shi X, Liu Y, Qi M, Lu Z, et al. 2017 Ythdc2 is an N6 -methyladenosine binding protein that regulates mammalian spermatogenesis. Cell Res. 27 1115-1127

Huan C, Li Z, Ning S, Wang H, Yu X-F and Zhang W 2018 Long Noncoding RNA uc002yug.2 activates HIV-1 latency through regulation of mRNA levels of various RUNX1 isoforms and increased tat expression. J. Virol. 92 e 01844

Huang S, Feng C, Zhai YZ, Zhou X, Li B, Wang LL, Chen W, Lv FQ and Li TS 2017 Identification of miRNA biomarkers of pneumonia using RNA-sequencing and bioinformatics analysis. Exp. Ther. Med. 13 1235-1244

Hussain S, Sajini AA, Blanco S, Dietmann S, Lombard P, Sugimoto Y, Paramor M, Gleeson JG, Odom DT, Ule J and Frye M 2013 NSun2-mediated cytosine-5 methylation of vault noncoding RNA determines its processing into regulatory small RNAs. Cell Rep. 4 255-261

Ichikawa T, Okuno Y, Sato Y, Goshima F, Yoshiyama H, Kanda T, Kimura H and Murata T 2018 Regulation of Epstein-Barr virus life cycle and cell proliferation by Histone H3K27 methyltransferase EZH2 in Akata cells. mSphere 3 e00478

Imai K, Ochiai K and Okamoto T 2009 Reactivation of Latent HIV-1 infection by the periodontopathic bacterium porphyromonas gingivalis involves histone modification. J. Immunol. 182 3688-3695

Imamura K, Takaya A, Ishida Y, Fukuoka Y, Taya T, Nakaki $\mathrm{R}$, Kakeda M, Imamachi N, et al. 2018 Diminished nuclear RNA decay upon Salmonella infection upregulates antibacterial noncoding RNAs. EMBO J. 37 e97723

Iyer LM, Zhang D and Aravind L 2016 Adenine methylation in eukaryotes: Apprehending the complex evolutionary history and functional potential of an epigenetic modification. BioEssays 38 27-40

Jabs S, Biton A, Bécavin C, Nahori MA, Ghozlane A, Pagliuso A, Spanò G, Guérineau V, et al. 2020 Impact of the gut microbiota on the m6A epitranscriptome of mouse cecum and liver. Nat. Commun. 111344

Jaenisch R and Bird A 2003 Epigenetic regulation of gene expression: How the genome integrates intrinsic and environmental signals. Nat. Genet. 33 245-254

Jeltsch A, Ehrenhofer-Murray A, Jurkowski TP, Lyko F, Reuter G, Ankri S, Nellen W, Schaefer M and Helm M 2017 Mechanism and biological role of Dnmt2 in nucleic acid methylation. RNA Biol. 14 1108-1123

Jenuwein T and Allis CD 2001 Translating the histone code. Science 293 1074-1080

Jiang G, Espeseth A, Hazuda DJ and Margolis DM 2007 c-Myc and Sp1 contribute to proviral latency by recruiting histone deacetylase 1 to the human immunodeficiency virus type 1 promoter. J. Virol. 81 10914-10923

Jose L, Ramachandran R, Bhagavat R, Gomez RL, Chandran A, Raghunandanan S, Omkumar RV, Chandra N, Mundayoor S and Kumar RA 2016 Hypothetical protein
Rv3423.1 of Mycobacterium tuberculosis is a histone acetyltransferase. FEBS J. 283 265-281

Kauder SE, Bosque A, Lindqvist A, Planelles V and Verdin E 2009 Epigenetic regulation of HIV-1 latency by cytosine methylation. S Ross. PLoS Pathog. 5 e1000495

Kibler CE, Milligan SL, Farris TR, Zhu B, Mitra S and McBride JW 2018 Ehrlichia chaffeensis TRP47 enters the nucleus via a MYND-binding domain-dependent mechanism and predominantly binds enhancers of host genes associated with signal transduction, cytoskeletal organization, and immune response. PLoS ONE 13 e0205983

Kim D, Lee J-Y, Yang J-S, Kim JW, Kim VN, Correspondence HC and Chang H 2020 The Architecture of SARSCoV-2 Transcriptome. Cell 181 914-921.e10

Kong W, Biswas A, Zhou D, Fiches G, Fujinaga K, Santoso $\mathrm{N}$ and Zhu J 2020 Nucleolar protein NOP2/NSUN1 suppresses HIV-1 transcription and promotes viral latency by competing with Tat for TAR binding and methylation. EM Campbell. PLOS Pathog. 16 e1008430

Koziol MJ, Bradshaw CR, Allen GE, Costa ASH, Frezza C and Gurdon JB 2016 Identification of methylated deoxyadenosines in vertebrates reveals diversity in DNA modifications. Nat. Struct. Mol. Biol. 23 24-30

Krishnananthasivam S, Jayathilaka N, Sathkumara HD, Corea E, Natesan M and De Silva AD 2017 Host gene expression analysis in Sri Lankan melioidosis patients. PLoS Negl. Trop. Dis. 11 e0005643

Krol J, Loedige I and Filipowicz W 2010 The widespread regulation of microRNA biogenesis, function and decay. Nat. Rev. Genet. 11 597-610

Kumar H, Lund R, Laiho A, Lundelin K, Ley RE, Isolauri E and Salminen S 2014 Gut microbiota as an epigenetic regulator: Pilot study based on whole-genome methylation analysis. Mbio 5 e02113-e2114

Kurth HM and Mochizuki K 2009 2'-O-methylation stabilizes Piwi-associated small RNAs and ensures DNA elimination in Tetrahymena. RNA 15 675-685

Li W 2019 HIV evades immune surveillance by methylation of viral RNA. Biochemistry 58 1699-1700

Latham T, MacKay L, Sproul D, Karim M, Culley J, Harrison DJ, Hayward L, Langridge-Smith P, et al. 2012 Lactate, a product of glycolytic metabolism, inhibits histone deacetylase activity and promotes changes in gene expression. Nucleic Acids Res. 40 4794-4803

Laurent L, Wong E, Li G, Huynh T, Tsirigos A, Ong CT, Low HM, Sung KWK, Rigoutsos I, Loring J and Wei CL 2010 Dynamic changes in the human methylome during differentiation. Genome Res. 20 320-331

Lebreton A, Lakisic G, Job V, Fritsch L, Tham TN, Camejo A, Matteï PJ, Regnaul B, et al. 2011 A bacterial protein targets the BAHD1 chromatin complex to stimulate type III interferon response. Science 331 1319-1321

Lee JY, Mehrazarin S, Alshaikh A, Kim S, Chen W, Lux R, Gwack Y, Kim RH, et al. 2019 Histone Lys demethylase KDM3C demonstrates anti-inflammatory effects by 
suppressing NF- $\mathrm{kB}$ signalling and osteoclastogenesis. FASEB J. 33 10515-10527

Lee J, Jang A, Kim JW, Han JH, Chun BH, Jung HS, Jeon CO and Myung SC 2017 Distinct histone modifications modulate DEFB1 expression in human vaginal keratinocytes in response to Lactobacillus spp. Probiotics Antimicrob. Proteins 9 406-414

Leonard MT, Davis-Richardson AG, Ardissone AN, Kemppainen KM, Drew JC, Ilonen J, Knip M, Simell O, et al. 2014 The methylome of the gut microbiome: Disparate Dam methylation patterns in intestinal Bacteroides dorei. Front. Microbiol. 5361

Leong MML, Cheung AKL, Dai W, Tsao SW, Tsang CM, Dawson CW, Ko JMY and Lung ML 2019 EBV infection is associated with histone bivalent switch modifications in squamous epithelial cells. Proc. Natl. Acad. Sci. USA 116 14144-14153

Li T, Lu Q, Wang G, Xu H, Huang H, Cai T, Kan B, Ge J and Shao F 2013 SET-domain bacterial effectors target heterochromatin protein 1 to activate host rDNA transcription. EMBO Rep. 14 733-740

Li E, Bestor TH and Jaenisch R 1992 Targeted mutation of the DNA methyltransferase gene results in embryonic lethality. Cell $69915-926$

Lichinchi G, Gao S, Saletore Y, Gonzalez GM, Bansal V, Wang Y, Mason CE and Rana TM 2016a Dynamics of the human and viral m(6)A RNA methylomes during HIV-1 infection of T cells. Nat. Microbiol. 116011

Lichinchi G, Zhao BS, Wu Y, Lu Z, Qin Y, He C and Rana TM 2016b Dynamics of human and viral RNA methylation during Zika virus infection. Cell Host Microbe 20 666-673

Lightfoot YL, Yang T, Sahay B and Mohamadzadeh M 2013 Targeting aberrant colon cancer-specific DNA methylation with lipoteichoic acid-deficient Lactobacillus acidophilus. Gut Microbes 4 84-88

Lindroth AM, Cao X, Jackson JP, Zilberman D, McCallum CM, Henikoff S and Jacobsen SE 2001 Requirement of CHROMOMETHYLASE3 for maintenance of CpXpG methylation. Science 292 2077-2080

Lister R, Pelizzola M, Kida YS, Hawkins RD, Nery JR, Hon G, Antosiewicz-Bourget J, Ogmalley R, et al. 2011 Hotspots of aberrant epigenomic reprogramming in human induced pluripotent stem cells. Nature 471 68-73

Lister R, Mukamel EA, Nery JR, Urich M, Puddifoot CA, Johnson ND, Lucero J, Huang Y, et al. 2013 Global epigenomic reconfiguration during mammalian brain development. Science 3411237905

Liu PT, Wheelwright M, Teles R, Komisopoulou E, Edfeldt K, Ferguson B, Mehta MD, Vazirnia A, et al. 2012 MicroRNA-21 targets the vitamin D-dependent antimicrobial pathway in leprosy. Nat. Med. 18 267-273

Liu J, Yue Y, Han D, Wang X, Fu Y, Zhang L, Jia G, Yu M, et al. 2014 A METTL3-METTL14 complex mediates mammalian nuclear RNA N6-adenosine methylation. Nat. Chem. Biol. 10 93-95

Liu S, Liu L, Xu G, Cao Z, Wang Q, Li S, Peng N, Yin J, et al. 2019 Epigenetic modification is regulated by the interaction of Influenza A virus nonstructural protein 1 with the de novo DNA methyltransferase DNMT3B and subsequent transport to the cytoplasm for K48-linked polyubiquitination. J. Virol. $93 \mathrm{e} 01587$

Lowndes NF and Toh GWL 2005 DNA repair: The importance of phosphorylating histone H2AX. Curr. Biol. 15 R99-102

Luo T, Kuriakose JA, Zhu B, Wakeel A and McBride JW 2011 Ehrlichia chaffeensis TRP120 interacts with a diverse array of eukaryotic proteins involved in transcription, signalling, and cytoskeleton organization. Infect. Immun. 79 4382-4391

Luo Tian and McBride Jere W 2012 Ehrlichia Chaffeensis TRP32 interacts with host cell targets that influence intracellular survival. Infect. Immun. 1128 154-112

Martin B, Coutard B, Guez T, Paesen GC, Canard B, Debart F, Vasseur JJ, Grimes JM, et al. 2018 The methyltransferase domain of the Sudan ebolavirus L protein specifically targets internal adenosines of RNA substrates, in addition to the cap structure. Nucleic Acids Res. 46 7902-7912

Masaki T, Qu J, Cholewa-Waclaw J, Burr K, Raaum R and Rambukkana A 2013 Reprogramming adult Schwann cells to stem cell-like cells by leprosy bacilli promotes dissemination of infection. Cell 152 51-67

Matsuda Y, Kobayashi-Ishihara M, Fujikawa D, Ishida T, Watanabe T and Yamagishi M 2015 Epigenetic heterogeneity in HIV-1 latency establishment. Sci. Rep. 57701

Maudet C, Mano M, Sunkavalli U, Sharan M, Giacca M, Förstner KU and Eulalio A 2014 Functional highthroughput screening identifies the miR-15 microRNA family as cellular restriction factors for Salmonella infection. Nat. Commun. 54718

Mauer J, Luo X, Blanjoie A, Jiao X, Grozhik AV, Patil DP, Linder B, et al. 2017 Reversible methylation of $\mathrm{m} 6 \mathrm{Am}$ in the $5^{\prime}$ cap controls mRNA stability. Nature 541 371-375

Mazurkiewicz P, Thomas J, Thompson JA, Liu M, Arbibe L, Sansonetti P and Holden DW 2008 SpvC is a Salmonella effector with phosphothreonine lyase activity on host mitogen-activated protein kinases. Mol. Microbiol. 67 1371-1383

Menachery VD, Schäfer A, Burnum-Johnson KE, Mitchell $\mathrm{HD}$, Eisfeld AJ, Walters KB, Nicora CD, Purvine SO, et al. 2018 MERS-CoV and H5N1 influenza virus antagonize antigen presentation by altering the epigenetic landscape. Proc. Natl. Acad. Sci. USA 115 E1012-1021

Miquel S, Martín R, Rossi O, Bermúdez-Humarán LG, Chatel JM, Sokol H, Thomas M, Wells JM and Langella P 2013 Faecalibacterium prausnitzii and human intestinal health. Curr. Opin. Microbiol. 16 255-261 
Mishra PK, Baum M and Carbon J 2011 DNA methylation regulates phenotype-dependent transcriptional activity in Candida albicans. Proc. Natl. Acad. Sci. USA $\mathbf{1 0 8}$ 11965-11970

Mitra S, Dunphy PS, Das S, Zhu B, Luo T and McBride JW 2018 Ehrlichia chaffeensis 2018 TRP120 effector targets and recruits host polycomb group proteins for degradation to promote intracellular infection. Infect. Immun. 86 e00845

Moffatt Catherine E and Lamont Richard J 2011 Porphyromonas gingivalis induction of microRNA-203 expression controls suppressor of cytokine signaling 3 in gingival epithelial cells. Infect. Immunity 79 2632-2637

Mojica SA, Hovis KM, Frieman MB, Tran B, Hsia RC, Ravel J, Jenkins-Houk C, Wilson KL, et al. 2015 SINC, a type III secreted protein of Chlamydia psittaci, targets the inner nuclear membrane of infected cells and uninfected neighbors. Mol. Biol. Cell 26 1918-1934

Mujtaba S, Winer BY, Jaganathan A, Patel J, Sgobba M, Schuch R, Gupta YK, Haider S, Wang R and Fischetti VA 2013 Anthrax SET protein: A potential virulence determinant that epigenetically represses $\mathrm{Nf}-\kappa \mathrm{B}$ activation in infected macrophages. J. Biol. Chem. 288 2345823472

Mukherjee S, Vipat VC and Chakrabarti AK 2013 Infection with influenza A viruses causes changes in promoter DNA methylation of inflammatory genes. Influenza Other Respi. Viruses 7 979-986

Murata M, Azuma Y, Miura K, Rahman MA, Matsutani M, Aoyama M, Suzuki H, Sugi K, et al. 2007 Chlamydial SET domain protein functions as a histone methyltransferase. Microbiology 153 585-592

Nakayama-Hosoya K, Ishida T, Youngblood B, Nakamura H, Hosoya N, Koga M, Koibuchi T, Iwamoto A and Kawana-Tachikawa A 2015 Epigenetic repression of Interleukin 2 expression in Senescent CD4 $+\mathrm{T}$ cells during chronic HIV type 1 infection. J. Infect. Dis. 211 28-39

Naqvi AR, Fordham JB, Khan A and Nares S 2014 MicroRNAs responsive to Aggregatibacter actinomycetemcomitans and Porphyromonas gingivalis LPS modulate expression of genes regulating innate immunity in human macrophages. Innate Immunity 20 540-551

O'Meara TR, Hay C, Price MS, Giles S and Alspaugh JA 2010 Cryptococcus neoformans histone acetyltransferase Gcn5 regulates fungal adaptation to the host. Eukaryot. Cell 9 1193-1202

Okano M, Bell DW, Haber DA and Li E 1999 DNA methyltransferases Dnmt3a and Dnmt3b are essential for de novo methylation and mammalian development. Cell 99 247-257

Olsen I, Singhrao SK and Osmundsen H 2017 Periodontitis, pathogenesis and progression: miRNA-mediated cellular responses to Porphyromonas gingivalis. J. Oral Microbiol. 91333396
Pacis A, Mailhot-Léonard F, Tailleux L, Randolph HE, Yotova V, Dumaine A, Grenier JC and Barreiro LB 2019 Gene activation precedes DNA demethylation in response to infection in human dendritic cells. Proc. Natl. Acad. Sci. USA 116 6938-6943

Palmer JM, Perrin RM, Dagenais TRT and Keller NP 2008 H3K9 methylation regulates growth and development in Aspergillus fumigatus. Eukaryot. Cell 7 2052-2060

Paroo Z, Liu Q and Wang X 2007 Biochemical mechanisms of the RNA-induced silencing complex. Cell Res. 17 187-194

Paschos K and Allday MJ 2010 Epigenetic reprogramming of host genes in viral and microbial pathogenesis. Trends Microbiol. 18 439-447

Pathak SK, Basu S, Bhattacharyya A, Pathak S, Banerjee A, Basu J and Kundu M 2006 TLR4-dependent NF-KB activation and mitogen- and stress-activated protein kinase 1-triggered phosphorylation events are central to Helicobacter pylori peptidyl prolyl cis -, trans -isomerase (HP0175)-mediated induction of IL-6 release from macrophages. J. Immunol. 40497950

Pathak SK, Tavares R, Klerk N, Spetz AL and Jonsson AB 2013 Helicobacter pylori protein JHP0290 binds to multiple cell types and induces macrophage apoptosis via tumor necrosis factor (TNF)-dependent and independent pathways. PLoS One 8 e77872

Paul B, Barnes S, Demark-Wahnefried W, Morrow C, Salvador C, Skibola C and Tollefsbol TO 2015 Influences of diet and the gut microbiome on epigenetic modulation in cancer and other diseases. Clin. Epigenetics 7112

Pennini ME, Perrinet S, Dautry-Varsat A and Subtil A 2010 Histone methylation by NUE, a novel nuclear effector of the intracellular pathogen Chlamydia trachomatis. PLoS Pathog. 9 e1000995

Pérez A, Castellazzi CL, Battistini F, Collinet K, Flores O, Deniz O, Ruiz ML, Torrents D, et al. 2012 Impact of methylation on the physical properties of DNA. Biophys. J. 102 2140-2148

Ping XL, Sun BF, Wang L, Xiao W, Yang X, Wang WJ, Adhikari S, Shi Y, et al. 2014 Mammalian WTAP is a regulatory subunit of the RNA N6-methyladenosine methyltransferase. Cell Res. 24 177-189

Pion M, Jaramillo-Ruiz D, Martínez A, Muñoz-Fernández MA and Correa-Rocha R 2013 HIV infection of human regulatory $\mathrm{T}$ cells downregulates Foxp3 expression by increasing DNMT3b levels and DNA methylation in the FOXP3 gene. AIDS 27 2019-2029

Pompei A, Cordisco L, Amaretti A, Zanoni S, Matteuzzi D and Rossi M 2007 Folate production by bifidobacteria as a potential probiotic property. Appl. Environ. Microbiol. 73 179-185

Ponting CP, Oliver PL and Reik W 2009 Evolution and functions of long noncoding RNAs. Cell 136 629-641

Prokop A, Gouin E, Villiers V, Nahori M-A, Vincentelli R, Duval M, Cossart P and Dussurget O 2017 OrfX, a 
nucleomodulin required for listeria monocytogenes virulence. Mbio 801550

Qu D, Sun WW, Li L, Ma L, Sun L, Jin X, Li T, Hou W, et al. 2019 Long noncoding RNA MALAT1 releases epigenetic silencing of HIV-1 replication by displacing the polycomb repressive complex 2 from binding to the LTR promoter. Nucleic Acids Res. 47 3013-3027

Raymond B, Batsche E, Boutillon F, Wu YZ, Leduc D, Balloy V, Raoust E, Muchardt C, et al. 2009 Anthrax lethal toxin impairs IL-8 expression in epithelial cells through inhibition of histone $\mathrm{H} 3$ modification. PLoS Pathog. 5 e1000359

Reik W, Dean W and Walter J 2001 Epigenetic reprogramming in mammalian development. Science. 293 1089-1093

Rennoll-Bankert KE, Garcia-Garcia JC, Sinclair SH and Dumler JS 2015 Chromatin bound bacterial effector AnkA recruits HDAC1 and modifies host gene expression. Cell. Microbiol. 17 1640-1652

Rolando M, Sanulli S, Rusniok C, Gomez-Valero L, Bertholet C, Sahr T, Margueron R and Buchrieser C 2013 Legionella pneumophila effector RomA uniquely modifies host chromatin to repress gene expression and promote intracellular bacterial replication. Cell Host Microbe 13 395-405

Roost C, Lynch SR, Batista PJ, Qu K, Chang HY and Kool ET 2015 Structure and thermodynamics of N6-methyladenosine in RNA: A spring-loaded base modification. $J$. Am. Chem. Soc. 137 2107-2115

Rosa JLD, Boyartchuk VL, Zhu LJ and Kaufman PD 2010 Histone acetyltransferase Rtt109 is required for Candida albicans pathogenesis. Proc. Natl. Acad. Sci. u. s. a. 107 1594-1599

Rossetto D, Avvakumov N and Côté J 2012 Histone phosphorylation: A chromatin modification involved in diverse nuclear events. Epigenetics 7 1098-1108

Roth SY, Denu JM and Allis CD 2001 Histone Acetyltransferases. Annu. Rev. Biochem. 70 81-120

Rothbart SB and Strahl BD 2014 Interpreting the language of histone and DNA modifications. Biochim. Biophys. Acta 1839 627-643

Roundtree IA, Evans ME, Pan T and He C 2017 Dynamic RNA modifications in gene expression regulation. Cell 169 1187-1200

Ruiz L, Delgado S, Ruas-Madiedo P, Sánchez B and Margolles A 2017 Bifidobacteria and their molecular communication with the immune system. Front. Microbiol. 82345

Sáenz Robles MT, Shivalila C, Wano J, Sorrells S, Roos A and Pipas JM 2013 Two independent regions of simian virus $40 \mathrm{~T}$ antigen increase $\mathrm{CBP} / \mathrm{p} 300$ levels, alter patterns of cellular histone acetylation, and immortalize primary cells. J. Virol. 87 13499-13509

Sahu MS, Patra S, Kumar K and Kaur R 2020 SUMOylation in human pathogenic Fungi: Role in physiology and virulence. J. Fungi 632
Saletore Y, Meyer K, Korlach J, Vilfan ID, Jaffrey S and Mason CE 2012 The birth of the Epitranscriptome: deciphering the function of RNA modifications. Genome Biol. 13175

Samba-Louaka A, Pereira J, Nahori MA, Villiers V, Deriano L, Hamon MA and Cossart P 2014 Listeria monocytogenes dampens the DNA damage response. PLoS Pathog. 10 e 1004470

Santos-Rosa H, Kirmizis A, Nelson C, Bartke T, Saksouk N, Cote J and Kouzarides T 2009 Histone H3 tail clipping regulates gene expression. Nat. Struct. Mol. Biol. 16 $17-22$

Schäfer A and Baric RS 2017 Epigenetic landscape during coronavirus infection. Pathogens 68

Schmeck B, Lorenz J, N'Guessan PD, Opitz B, van Laak V, Zahlten J, Slevogt H, Witzenrath M, et al. 2008 Histone acetylation and flagellin are essential for Legionella pneumophila -INDUCED cytokine expression. J. Immunol. 181 940-947

Schreiner S, Wimmer P, Sirma H, Everett RD, Blanchette P, Groitl P and Dobner T 2010 Proteasome-dependent degradation of Daxx by the viral E1B-55K protein in human adenovirus-infected cells. J. Virol. 84 7029-7038

Schuelein R, Spencer H, Dagley LF, Pf Li, Luo L, Stow JL, Abraham G, Naderer T, et al. 2018 Targeting of RNA polymerase II by a nuclear Legionella pneumophila Dot/ Icm effector SnpL. Cell. Microbiol. 20 e12852

Schulte LN, Eulalio A, Mollenkopf HJ, Reinhardt R and Vogel J 2011 Analysis of the host microRNA response to salmonella uncovers the control of major cytokines by the Let-7 family. EMBO J. 30 1977-1989

Shamay M, Krithivas A, Zhang J and Hayward SD 2006 Recruitment of the de novo DNA methyltransferase Dnmt3a by Kaposi's sarcoma-associated herpesvirus LANA. Proc. Natl. Acad. Sci. USA 103 1455414559

Sharma G, Sowpati DT, Singh P, Khan MZ, Ganji R, Upadhyay S, Banerjee S, Nandicoori VK and Khosla S 2016 Genome-wide non-CpG methylation of the host genome during M. tuberculosis infection. Sci. Rep. 6 25006

Sharma G, Upadhyay S, Srilalitha M, Nandicoori VK and Khosla S 2015 The interaction of mycobacterial protein Rv2966c with host chromatin is mediated through nonCpG methylation and histone $\mathrm{H} 3 / \mathrm{H} 4$ binding. Nucleic Acids Res. 43 3922-3937

Shi DQ, Ali I, Tang J and Yang WC 2017 New insights into 5hmC DNA modification: Generation, distribution and function. Front. Genet. 8100

Slevogt H, Schmeck B, Jonatat C, Zahlten J, Beermann W, Van Laak V, Opitz B, Dietel S, et al. 2006 Moraxella catarrhalis induces inflammatory response of bronchial epithelial cells via MAPK and NF- $\mathrm{BB}$ activation and histone deacetylase activity reduction. Am. J. Physiol. Lung Cell. Mol. Physiol. 290 L818-L826 
Squires JE, Patel HR, Nousch M, Sibbritt T, Humphreys DT, Parker BJ, Suter CM and Preiss T 2012 Widespread occurrence of 5-methylcytosine in human coding and non-coding RNA. Nucleic Acids Res. 40 50235033

Squires JE and Preiss T 2010 Function and detection of 5-methylcytosine in eukaryotic RNA. Epigenomics 2 709-715

Tahiliani M, Koh KP, Shen Y, Pastor WA, Bandukwala H, Brudno Y, Agarwal S, Iyer LM, et al. 2009 Conversion of 5-methylcytosine to 5-hydroxymethylcytosine in mammalian DNA by MLL partner TET1. Science. 324 930-935

Thamban T, Agarwaal V and Khosla S 2020 Role of genomic imprinting in mammalian development. $J$. Biosci. 4520

Tolg C, Sabha N, Cortese R, Panchal T, Ahsan A, Soliman A, Aitken KJ, Petronis A, et al. 2011 Uropathogenic E. coli infection provokes epigenetic downregulation of CDKN2A (p16INK4A) in uroepithelial cells. Lab. Investig. 91 825-836

Toth Z, Maglinte DT, Lee SH, Lee HR, Wong LY, Brulois KF, Lee S, Buckley JD, et al. 2010 Epigenetic analysis of KSHV latent and lytic genomes P Kellam. PLoS Pathog. 6 e1001013

Turnbaugh PJ, Ley RE, Hamady M, Fraser-Liggett CM, Knight R and Gordon JI 2007 The human microbiome project. Nature $449804-810$

Turner BM 2002 Cellular memory and the histone code. Cell $111285-291$

Varghese TA, Jayasri MA and Suthindhiran K 2015 Marine Actinomycetes as potential source for histone deacetylase inhibitors and epigenetic modulation. Lett. Appl. Microbiol. 61 69-76

Vdovikova S, Gilfi S, Wang S, Dongre M and Wai SN 2018 Modulation of gene transcription and epigenetics of colon carcinoma cells by bacterial membrane vesicles. Sci. Rep. 87434

Viswanathan T, Arya S, Chan SH, Qi S, Dai N, Misra A, Park JG, Oladunni F, et al. 2020 Structural basis of RNA cap modification by SARS-CoV-2. Nat. Commun. 11 3718

Wakeel A, den Dulk-Ras A, Hooykaas PJJ and McBride JW 2011 Ehrlichia chaffeensis tandem repeat proteins and Ank200 are type 1 secretion system substrates related to the repeats-in-toxin exoprotein family. Front. Cell. Infect. Microbiol. 122

Walter J 2008 Ecological role of lactobacilli in the gastrointestinal tract: Implications for fundamental and biomedical research. Appl. Environ. Microbiol. $\mathbf{7 4}$ 4985-4996

Wexler HM 2007 Bacteroides: The good, the bad, and the nitty-gritty. Clin. Microbiol. Rev. 20 593-621

Worton LE, Gardiner EM, Kwon RY, Downey LM, Ausk BJ, Bain SD and Gross TS 2018 Botulinum toxin
A-induced muscle paralysis stimulates Hdac4and differential miRNA expression. PLoS One 13 e0207354

Xia X 2020 Extreme genomic CpG deficiency in SARS$\mathrm{CoV}-2$ and evasion of host antiviral defense. Mol. Biol. Evol. 37 2699-2705

Xia G, Schneider-Stock R, Diestel A, Habold C, Krueger S, Roessner A, Naumann M and Lendeckel U 2008 Helicobacter pylori regulates p21WAF1 by histone H4 acetylation. Biochem. Biophys. Res. Commun. 369 $526-531$

Xiao W, Adhikari S, Dahal U, Chen YS, Hao YJ, Sun BF, Sun HY, Li A, et al. 2016 Nuclear m6A reader YTHDC1 regulates mRNA splicing. Mol. Cell 61 507-519

Xiao CL, Zhu S, He M, Chen D, Zhang Q, Chen Y, Yu G, Liu J, et al. 2018 N 6 -Methyladenine DNA modification in the human genome. Mol. Cell 71 306-318

Xu J and Gordon JI 2003 Honor thy symbionts. Proc. Natl. Acad. Sci. u. s. a. 100 10452-10459

Yan J, Zhang M, Zhang J, Chen X and Zhang X 2011 Helicobacter pylori infection promotes methylation of WWOX gene in human gastric cancer. Biochem. Biophys. Res. Commun. 408 99-102

Yaseen I, Kaur P, Nandicoori VK and Khosla S 2015 Mycobacteria modulate host epigenetic machinery by Rv1988 methylation of a non-tail arginine of histone H3. Nat. Commun. 68922

Yin L and Chung WO 2011 Epigenetic regulation of human B-defensin 2 and $\mathrm{CC}$ chemokine ligand 20 expression in gingival epithelial cells in response to oral bacteria. Mucosal Immunol. 4 409-419

Yuan J, Pu M, Zhang Z and Lou Z 2009 Histone H3-K56 acetylation is important for genomic stability in mammals. Cell Cycle 8 1747-1753

Zaccara S, Ries RJ and Jaffrey SR 2019 Reading, writing and erasing mRNA methylation. Nat. Rev. Mol. Cell Biol. 20 608-624

Zapata JC, Campilongo F, Barclay RA, DeMarino C, Iglesias-Ussel MD, Kashanchi F and Romerio F 2017 The Human Immunodeficiency Virus 1 ASP RNA promotes viral latency by recruiting the Polycomb Repressor Complex 2 and promoting nucleosome assembly. Virology 506 34-44

Zhan S, Wang T, Ge W and Li J 2018 Multiple roles of Ring 1 and YY1 binding protein in physiology and disease. $J$. Cell. Mol Med. 22 2046-2054

Zhang G, Huang H, Liu D, Cheng Y, Liu X, Zhang W, Yin $\mathrm{R}$, Zhang D, et al. 2015 N6-methyladenine DNA modification in Drosophila. Cell 161 893-906

Zheng G, Dahl JA, Niu Y, Fedorcsak P, Huang CM, Li CJ, Vågbø CB, Shi Y, et al. 2013 ALKBH5 is a mammalian RNA demethylase that impacts RNA metabolism and mouse fertility. Mol. Cell 49 18-29

Zhu B, Nethery KA, Kuriakose JA, Wakeel A, Zhang X and McBride JW 2009 Nuclear translocated Ehrlichia chaffeensis ankyrin protein interacts with a specific adenine- 
rich motif of host promoter and intronic Alu elements. Zughaier SM, Rouquette-Loughlin CE and Shafer WM 2020 Infect. Immun. 77 4243-4255

Zoghbi HY, Beaud, et al. 2016 Epigenetics and human disease. Cold Spring Harb. Perspect. Biol. 89497 Identification of a Neisseria gonorrhoeae histone deacetylase: Epigenetic impact on host gene expression. Pathogens 9132

Corresponding editor: Sagar SEnguPta 